\title{
Quantitative characterisation of seafloor substrate and bedforms using advanced processing of multibeam backscatter-Application to Cook Strait, New Zealand
}

\author{
Geoffroy Lamarche ${ }^{\mathrm{a},{ }^{*}}$, Xavier Lurton ${ }^{\mathrm{b}}$, Anne-Laure Verdier $^{\mathrm{a}}$ and Jean-Marie Augustin ${ }^{\mathrm{b}}$
}

\author{
${ }^{a}$ National Institute of Water and Atmospheric Research (NIWA) Ltd, Private Bag 14-901, Wellington \\ 6241, New Zealand \\ ${ }^{\mathrm{b}}$ Institut Français de Recherche pour l'Exploitation de la Mer (IFREMER), BP70, 29280 Plouzané, \\ France
}

* Corresponding author : Geoffroy Lamarche, Tel.: +64 4386 0465; fax: +64 438621 53, email address : g.lamarche@niwa.co.nz

\begin{abstract}
:
A comprehensive EM300 multibeam echo-sounder dataset acquired from Cook Strait, New Zealand, is used to develop a regional-scale objective characterisation of the seafloor. Sediment samples and high-resolution seismic data are used for ground-truthing. SonarScope ${ }^{\circledR}$ software is used to process the data, including signal corrections from sensor bias, specular reflection compensation and speckle noise filtering aiming at attenuating the effects of recording equipment, seafloor topography, and water column. The processing is completed by correlating a quantitative description (the Generic Seafloor Acoustic Backscatter-GSAB model) with the backscatter data. The calibrated Backscattering Strength $(B S)$ is used to provide information on the physical characteristics of the seafloor. The imagery obtained from the BS statistical compensation is used for qualitative interpretation only; it helps characterizing sediment facies variations as well as geological and topographic features such as sediment waves and erosional bedforms, otherwise not recognised with the same level of detail using conventional surveying. The physical BS angular response is a good indicator of the sediment grain size and provides a first-order interpretation of the substrate composition. $B S$ angular response for eight reference areas in the Narrows Basin are selected and parameterised using the GSAB model, and $B S$ angular profiles for gravelly, sandy, and muddy seafloors are used as references for inferring the grain size in the reference areas. We propose to use the calibrated $B S$ at $45^{\circ}$ incidence angle $\left(B S_{45}\right)$ and the Specular-To-Oblique Contrast (STOC) as main global descriptors of the seafloor type. These two parameters enable global backscatter studies by opposition to compensated imagery whose intensity is not comparable from one zone to the other. The results obtained highlight the interest of $B S$ measurements for seafloor remote sensing in a context of habitat-mapping applications.
\end{abstract}

Keywords: Backscatter; Multibeam echo-sounder; Sediment waves; Habitat mapping 


\section{1 - INTRODUCTION}

The increasing need for the sustainable management of the marine environment and resources requires obtaining objective and quantitative descriptors of seafloor habitats from remote-sensed data. The potential for characterizing the nature of the seafloor using the acoustic reflectivity (or backscatter) collected routinely with multibeam echo-sounders (MBES) has been recognised for at least 20 years (e.g., de Moustier, 1986). However, quantitative analysis of backscatter data for seafloor characterization has only resurfaced recently for these types of applications (Anderson et al., 2008; Ehrhold et al., 2006; Le Gonidec et al., 2003; Medialdea et al., 2008; Wright and Heyman, 2008).

Quantitative models of the relationship between the acoustic backscatter and geological substrate properties fall into three categories: 1) physical process modelling addressing links between physical processes (sound propagation in inhomogeneous media and acoustic wave scattering by rough interfaces and volume heterogeneity), 2) geoacoustical modelling relating the physical parameters of the sediments with their geological description; and 3) phenomenological models, based on heuristical descriptors and parameters, aimed at a global model of intricate physical phenomena perceived as too complex either for justifying a rigorous physical approach or for making possible inversion processes. 
Physical and geoacoustical models are best suited to interpreting fundamental phenomena observable on simplified or ideal features (Fonseca et al., 2002; Hughes Clarke et al., 1996; McRea Jr et al., 1999; Mourad and Jackson, 1989; Novarini and Caruthers, 1998). Phenomenological models have been developed for experimental data exploitation (Augustin et al., 1996; Le Chenadec et al., 2007; Lurton, 2003a). Accurate physical modelling provides insight in the phenomena involved in sonar signal backscattering - in the sense that it makes explicit the intrinsic potential dependence of backscattered echoes upon geological substrate composition (Mulhearn, 2000; Pratson and Edwards, 1996), However this approach is unavoidably limited to ideally simplified configurations making it possible to build a theoretical model of acceptable complexity; hence it is generally inappropriate for providing unsupervised (objective) inversion tools for accurately retrieving sediment characteristics directly from the backscatter data, except in tightly constrained contexts where the model applicability is known a priori (Hughes Clarke et al., 1997; Jackson et al., 1986). It therefore remains still very much questionable as to whether such numerical models may provide the expected link between seafloor remote sensing and habitat mapping. A difficult and often under-estimated problem is that the accurate retrieval of physical $B S$ values has to go through a thorough compensation of the sensor characteristics (Ryan and Flood, 1996). Despite progress in the most recent MBES systems, the built-in compensation and basic 
processing do not allow an accurate enough determination of absolute $B S$ and incidence angles required for any quantitative analysis of the backscatter signal (Hellequin et al., 1997; Hughes Clarke et al., 1996; Le Gonidec et al., 2003).

This study aims at showing the potential provided by fully-processed backscatter data to characterize the seafloor in a variety of geological and sedimentological environments, using a MBES data set from the Cook Strait, New Zealand (Figure 1). The first part of the paper undertakes a qualitative interpretation of the normalised backscatter imagery, with a particular focus on well-developed sediment waves, from which we discuss the potential benefit brought by backscatter data to quantify the geometrical and geological characteristics of sediment bedforms. We then apply an improved version of the heuristical model for angular $B S$ proposed by Lurton (2003a) and Augustin and Lurton (2005) to various responses recorded in central Cook Strait. This approach enables us to propose a quantitative interpretation of the backscatter over a variety of environments and bedform, and work toward the classification and geological interpretation of $B S$ using the model parameters. We attempt to retrieve the seafloor sediment type from the derived relationship between sediment mean grain size and $B S$ angular response. We finally discuss the methodological difficulties encountered and propose practical solutions for future research aiming at a generalisation to this approach. 
Our objective purpose is not to propose new models in backscattering or geoacoustics. Rather, we seek to emphasise the value of quantitative backscatter data analysis for investigating the submarine environment at a regional scale from shallow continental shelf to deep ocean water depths, by using a pragmatic, rigorously controlled, approach to backscatter data analysis.

\section{2 - CoOK Strait Geological Setting}

The diverse and complex geomorphology of Cook Strait is the result of dynamic climatic, tectonic and oceanic forcings that impacted on the region since at least the last post-glacial period (Lewis et al., 1994). Cook Strait, between the North and South Islands of New Zealand (Figure 1), is of strategic public and economic interest for New Zealand containing: electrical power cables joining the two islands; major tectonic faults (Van Dissen and Berryman, 1996); and economically important fish stocks and biological resources.

A series of canyons has been carved into the continental shelf of Cook Strait (Mountjoy et al., 2009), with walls up to $1100 \mathrm{~m}$ in height. Instability of the canyon walls is suggested by multiple semi-circular scars in their upper section with debris accumulating in the canyon floors. Beyond the continental slope, the canyons flow into the Hikurangi Trough infilled with thick turbidite sequences and host to the Hikurangi channel (Lewis et al., 1994). The shelf edge is defined at $\sim 150 \mathrm{~m}$ water depth 
beyond which the continental slope descends to more than $2500 \mathrm{~m}$ water depth in the Hikurangi Trough.

During the Last Glacial Maximum, the continental shelf flanking Cook Strait was an emergent coastal plain (Carter, 1992; Lewis et al., 1994). As sea-level rose from ca-150m, a wave-based erosional surface was formed around the Straits. Most of this transgressive surface was subsequently blanketed by a wedge of post-glacial mud. However, strong waves and tidal forcing have left some areas of the shelf bare of post-glacial sedimentation so that the erosional surface outcrops at the seafloor ((Lewis et al., 1994; Mountjoy et al., 2009).

Today powerful tidal currents, with peak flows reaching $1.5 \mathrm{~m} / \mathrm{s}$ in the narrowest passage of Cook Strait, known as the Narrows, coupled with strong sediment delivery from North and South island's rivers (Hicks and Shankar, 2003), have produced distinctive patterns of sedimentation. In particular, several sediment wave fields were broadly recognised in the Narrows Basin (Carter, 1992).

In addition to the ecological diversity to be expected from such a complex environment, Cook Strait hosts a large diversity of faunal ecosystems associated with active and relict fluid seeps such as carbonate chimneys and concretions, and reflective plumes generated (Barnes et al., 2009; Lewis et al., 1994, Law et al., 2009). Seeps and cold-fluid vents are usually associated with rich, distinctive, chemosynthetic faunas, which stress the importance of marine environment management for the region. 


\section{3 - DATA AND Methods}

\subsection{Data acquisition}

MBES data was collected during six oceanographic surveys of R.V. Tangaroa between 2001 and 2005 in Cook Strait by the National Institute of Water and Atmosphere (NIWA) (Table 1). The total surveyed area is ca. $8500 \mathrm{~km}^{2}$ in depths greater than ca. $150 \mathrm{~m}$ (Figure 1). Tangaroa has a hull-mounted Kongsberg EM300 (32 kHz) MBES (Table 2), that fully compensates the vessel position and motion (heave, pitch, roll, and yaw). Sound velocity measurements were performed at regular intervals to account for hydrology effects. Bathymetry data were routinely processed onboard using C\&C Technologies HydroMap and ArcInfo software. A large geophysical and geological data dataset including multichannel and high resolution seismic reflection data, sediment cores, seafloor grab samples and photographs are available for the region (Carter, 1992; Lewis et al., 1994) and provided means to ground-truth the remote-sensed data analysis.

\subsection{Backscatter Data Processing}

The aim of backscattered signal processing is to provide an interpretable image, and to estimate descriptive parameters relating the $B S$ with geological properties. The data is inherently noisy and requires processing to remove artefacts attributable to the recording equipment, seafloor topography and water column properties (Hellequin et al., 1997; Hellequin et al., 2003; Le Gonidec et al., 2003). 
The echo level $(E L)$ at the receiver's output is primarily associated with the seafloor backscattering strength $(B S(\theta))$, where $\theta$ is defined as the ray-path incidence angle onto the seafloor obtained from the refraction estimated during bathymetry processing and from the locally computed digital terrain model (DTM). EL depends on transmission loss (TL), which depends on transmission range $(R)$ and on water column absorption coefficient $(\alpha)$; the sonar characteristics (transmitted source level $S L$, signal duration $T$, transmission and reception directivity patterns $D_{T}$ and $D_{R}$; receiver gain $G_{R}$; hydrophone sensitivity $S_{H}$ ); and the insonified area $A(R, \theta, T)$ (Lurton, 2003a). $S L, D_{T}, S_{H}, D_{R}$, and $G_{R}$ are hardware dependent. Hydrology conditions influence absorption $(\alpha)$ and incidence angle $(\theta)$, whereas the geometrical configuration (water depth, topography) controls both the range $(R)$ and $(\theta)$. These parameters are gathered into the conventional sonar equation (Lurton, 2003a, 2003b) :

$$
E L=S L+D_{T}-2 . T L+10 \log A+B S+S_{H}+D_{R}+G_{R}
$$

Practically, there are two issues in processing $B S$ data for enhanced application for geological interpretation: sonar calibration which controls the physical signal levels provided by the sensor, and recorded data correction required for qualitative and quantitative backscatter estimation and exploitation.

\subsubsection{Sonar Calibration}

Two levels of amplitude calibration may be applied on any sonar data: 
1) An elementary calibration to ensure that the sonar parameters ( $S L, T$, $\left.D_{T}, D_{R}, G_{R}\right)$ are correctly accounted for, in the recorded amplitude levels; this guarantees that the data are repeatable, and do not depend on the system settings; ideally this is done through built-in compensations applied in the receiver;

2) A full calibration procedure to provide exact referenced values for the transmitted level and the receiving sensitivity. This requires factory calibration of transducers and electronics, and implementation of control tools and procedures to ensure that these parameters are checkable and compensable onboard.

Despite significant improvements, the built-in corrections applied by MBES (Kongsberg, 1997) still remain imperfect and may result in artefacts in the backscatter data, precluding accurate qualitative and quantitative data analysis. Therefore to improve data quality, built-in compensations applied at data acquisition must therefore be removed and replaced by more accurate ones. Unfortunately, some of the system characteristics are not directly accessible and have to be deduced from the recorded data. For instance the echo level modulation caused by the array directivity patterns are corrected by fitting a modelled pattern on data recorded over several assumed-homogeneous seafloor areas (Figure 2) (Lurton et al., 1997). This technique is similar to that applied to satelliteborne radar reflectivity data for a posteriori compensation of directivity patterns (Maître, 2001). 
The amplitude calibration used in fishery acoustics, measuring the response of a reference spherical target (e.g. Foote, 1980), can be applied to high-frequency MBES in a controlled environment (Foote et al., 2005); however it is not practical for low-frequency MBES featuring long arrays already mounted on ship's hull. In this study, we retained the manufacturer values for the transmitted levels and receiver sensitivity; the risks of this simplification being either an inaccurate qualification of the hardware by the manufacturer, or a possible drift of the system with time.

\subsubsection{Data Correction}

For qualitative analysis of the sonar images, an echo-level compensation needs to be applied on the data. This process removes artefacts inherent in the sensor and corrects the signal angular response to produce a normalized image interpretable by end-users (Figure 3). Largest errors are produced by the specular echo at nadir and the reflectivity fall-off at grazing angles. Echo-level compensation requires that the normalised level is taken at a significant and relevant value, in particular respecting the contrast between the $B S$ levels associated with different sediment types. Finally, an additional absolute calibration of the $B S$ data must be carried out for any satisfactory quantitative analysis to be undertaken.

\subsubsection{Methodology applied to the Cook Strait Data}

The Cook Strait dataset was processed using the SonarScope ${ }^{\circledR}$ software developed by IFREMER, France (Augustin and Lurton, 2005) 
(http://www.ifremer.fr/fleet/acous_sism/sonarscope/index.html).

In

SonarScope ${ }^{\circledR}$ the physical parameters (bathymetry, backscatter level, incidence angle, motion, etc.) are displayed as different layers available for simultaneous or combined processing using either conventional or sonar-specific signal and image processing modules. Advanced processing techniques include signal calibration and compensation, speckle noise filtering, texture analysis, and image segmentation.

The compensation process was undertaken in three steps: 1) correction for transmission losses associated with absorption given by changing hydrological conditions; 2) estimation of the array directivity patterns, from which specific gains were applied for each angular sector of the sounder; and 3) correction for the instantaneous signal footprint area, as a function of incident angle, directivity pattern aperture, and pulse duration.

Attenuation of the strong, sometimes obliterating, echo associated with the specular reflection in backscatter images is a fundamental step prior to any qualitative analysis (Figure 3). In the present case, the specular signal was filtered out by statistical compensation (Augustin and Lurton, 2005) consisting in subtracting from the physical angle-dependent sonar image (Figure 3C) an average $B S(\theta)$, hence flattening the angular dependence while preserving the average $B S$ value. The resulting image is more "readable" since the contrast is enhanced because the corrected $B S$ values are close to the mean value (Figure 3B). However, this compensated image has lost most of the $B S$ level information, since it was normalized to 
an arbitrarily-chosen reference level (in this study we used the uncompensated value at $45^{\circ}$ ), and it is hence exploitable mainly in terms of relative intensity.

It is emphasised that a fundamental distinction has to be made between the compensated backscatter, normalized at a conventional reference level, defined for imagery purposes and usable for qualitative analysis, and the physically-correct calibrated $B S$ used for quantitative analysis. The two types of data are expressed in $\mathrm{dB}$ per $\mathrm{m}^{2}$ (simplified as $\mathrm{dB}$ ) and both are incorporated in the geological-oriented analysis of reflectivity data.

\subsection{Backscatter Angular Profile Modelling}

We used the Generic Seafloor Acoustic Backscatter (GSAB) model to represent the $B S$ angular response. The GSAB was firstly developed within the framework of directivity pattern compensations for MBES data (Hellequin et al., 1997) and used since in various contexts (Augustin and Lurton, 2005; Guillon and Lurton, 2001; Le Chenadec and Boucher, 2005; Le Chenadec et al., 2007; Lurton, 2003b). However, it has never been systematically applied to a large regional data set. The GSAB model represents the $B S$ angular response as a combination of a Gaussian law for the specular angles and Lambert-like law for grazing angles (Figure 4). In its original form, it uses four descriptors ( $A$ to $D$ ), with no explicit relationship with the geological or acoustical attributes used classically in these disciplines (e.g., Jackson et al., 1986). The model is given by: 


$$
B S(\theta)=10 \log \left[A \cdot \exp \left(-\theta^{2} / 2 B^{2}\right)+C \cdot \cos ^{D} \theta\right]
$$

where

$A$ quantifies the specular maximum amplitude. In the tangent-plane approach (Brekhovskikh and Lysanov, 1982). $A$ is related to the coherent reflection coefficient at the water-seabed interface, and is therefore high for smooth sediment interfaces (at the acoustic wavelength's scale), and for strong water-sediment impedance contrasts (Lurton 2003a).

$B$ quantifies the angular extent of the specular regime. In the tangent-plane model, it represents the facet slope variance and is therefore an interface roughness descriptor. Note that, in the following, angular extent denotes the half-width of the specular peak actually measured by MBES working over both sides of nadir.

$C$ quantifies the average $B S$ level at oblique incidence. It is the offset associated with Lambert's law describing $B S$ at intermediate angles for rough interfaces, and includes the contribution of the volume inhomogeneity backscatter. $C$ increases with frequency, seafloor roughness and impedance, and heterogeneities present inside the sediment volume. Typically $10 \log C$ ranges from -20 to $-30 \mathrm{~dB}$, but values between 15 and $-40 \mathrm{~dB}$ are commonly observed.

$D$ is the backscatter angular decrement, commanding the fall-off at grazing angles. It is high for soft and smooth sediment interfaces. According to the laws of Lommel-Silliger and Lambert, $D$ is equal to 1 and 2, respectively (Lurton, 2003a). 
While this four-parameter model $(A, B, C, D)$ is adequate to model the backscatter angular behaviour in many configurations, in some cases the model may require an intermediate term to account for the smooth transition between the specular and the lateral modes. This transitory component is modelled with a second Gaussian law; equation (2) becomes:

$$
B S(\theta)=10 \log \left[A \cdot \exp \left(-\theta^{2} / 2 B^{2}\right)+C \cdot \cos ^{D} \theta+E \cdot \exp \left(-\theta^{2} / 2 F^{2}\right)\right]
$$

where $E$ is the transitory maximum level $(\mathrm{dB})$, and $F$ its angular halfextent (in deg) (Figure 4). There has been no study on the relationship of $\mathrm{E}$ and F to geological and physical seafloor properties. Their secondary role will be addressed in the discussion. This improved form (3) of GSAB will be used in the following.

Since GSAB aims at providing angle dependence descriptors of a swath sonar dataset, the coefficients are only valid for a given sonar frequency. Today's current MBES uses one of seven nominal frequencies (12; 32; 70; $100 ; 200 ; 300$; and $450 \mathrm{kHz}$ ) each corresponding to different practical applications.

\subsection{Sample analysis}

The sample database consists of 260 seafloor samples collected since the late 1950's by the New Zealand Oceanographic Institute (NZOI) and subsequently by NIWA, using gravity corer, piston corer and seafloor grab. Sedimentological analysis consisted of grain size analysis and 
classification as a function of the percentage of mud, gravel and sand undertaken using standard procedure for all samples. Mean grain sizes were obtained using a laser granulometer and the Gradistat programme (Blott and Pye, 2000) for statistical analysis of unconsolidated sediments. The samples are classified in three groups based on log-normal distribution from their $\varphi$ (phi) values, where $\varphi=-\log _{2} d$, where $d$ is the grain diameter in millimetres (Table 3).

\section{4 - Results}

\subsection{Bathymetry and Backscatter Imagery}

Although the morphological complexity of the Cook Strait is well expressed in the bathymetry (Figure 1), the compensated backscatter imagery provides complementary detailed information about seafloor features and substrates (Figure 5). At the scale of the Cook Strait region, we define three basic imagery facies 1) a homogeneous, weak-to-moderate reflectivity (dark grey) facies, 2) a homogeneous, highly reflective (light grey) facies, and 3) a highly heterogeneous reflective facies. Using these three facies as end-members of a continuum we define four regions: the Narrows, the continental shelf, the continental slope and canyons, and the Hikurangi Trough.

The Narrows correspond to the 350 m-deep, N-S trending oval Narrows Basin and its steep, linear, eastern and western walls. The continental shelf on either sides of the basin is less than $6 \mathrm{~km}$ wide. It is smooth and 
homogeneous on the west and rough to the east, along the Wellington Peninsula. In terms of imagery, the Narrows Basin divides into a northern weak-to-moderate (dark) and a southern moderate-to-strong (light) facies. The floor of the Narrows Basin has a weak backscatter facies, whereas it is strong on its flanks. A region of strong to very-strong imagery extends well southward of the Narrows to the head of the Cook Strait canyon (Figure 6). The $B S$ dynamic over the Narrow Basin from Oceanographic voyage Tan0105 alone is $18 \mathrm{~dB}$ above the $3 \%$ quantile (Table 4). The floor and eastern wall of the Narrows Basin is dominated by fields of sediment waves; these are characterised by a distinct $\mathrm{E}-\mathrm{W}$ orientation, i.e. perpendicular to the long axis of the Narrows Basin, and asymmetric shapes with steeper NE flanks. The largest sediment waves are up to $10 \mathrm{~m}$ in height with a ca. $250 \mathrm{~m}$ wavelength, and the smallest waves are $2-4 \mathrm{~m}$ high with a wavelength less than $100 \mathrm{~m}$ (Figure 7). The backscatter over the sediment wave field is characteristically very weak to weak (dark).

The continental shelf is poorly covered by EM300 since this equipment is not well-adapted for water depths shallower than $\sim 100 \mathrm{~m}$. At this relatively coarse regional scale, the shelf appears smooth and homogenous. The shelf break is well marked at $\sim 160 \mathrm{~m}$ below sea level, except in areas where landsliding has prograded and eroded the top of the continental slope (Mountjoy et al., 2009). The continental shelf shows a weak-to-moderate (medium grey) and homogeneous backscatter. The $B S$ dynamic over the continental shelf is ca. $10 \mathrm{~dB}$ above the $3 \%$ quantile. 
The continental slope, in the east and SE of the study area has a very rough topography associated with canyon flanks and steep gullies. The steep gradients, blocky facies on the canyons floors, and multiple circular scarps at the top of the continental results in a highly heterogeneous imagery facies (Figure 5), with a $B S$ dynamic of $19 \mathrm{~dB}$ above the $3 \%$ quantile. The canyon floors along the continental slope show a strong to very strong reflectivity contrasting with the low values on the flanks. This is best exemplified over the Opouawe and Pahaua canyons.

The Hikurangi Trough has a smooth topography associated with a moderate (light grey), very homogeneous imagery facies. The $16 \mathrm{~dB}$ dynamic of the $B S$ above the $3 \%$ quantile, is likely to be the result of the particular contribution of the specular reflection which remains high in all cases.

\subsection{Characterisation of sediment bedforms}

The backscatter dependence with the micro-topography provides an excellent means to identify bedforms. In the Narrows Basin, the multibeam bathymetry provides clear information on the geometry of sediment waves (amplitude, orientation, wavelength, asymmetry, and along-crest length, Figures 7 and 8). Low backscatter level is consistently observed on the sediment wave crests, and strong levels in the troughs; a typical pattern already noted by e.g., Fonseca et al. (2009) and Goff et al. (2000). Over the Narrows Basin the $B S$ varies with a very strong dynamic 
of $13 \mathrm{~dB}$, for bathymetric amplitudes ranging from 3 to $5 \mathrm{~m}$. The average crest-to-trough $B S$ dynamics is $\sim 6 \mathrm{~dB}$ across any of the sediment waves, i.e. well within the equipment $1 \mathrm{~dB}$ resolution (Kongsberg, 1997).

The variation in reflectivity across sediment waves is not related to an effect of the incidence angle. In some areas within the Narrows Basin the $B S$ modulation contrast is still high with crest-to-trough $B S$ dynamics from 3 to $7 \mathrm{~dB}$ producing sediment wave patterns on the $B S$ imagery (Figure 8A). However, these sediment waves cannot be detected in the bathymetry (Figure 8B). The incidence angles across the sediment waves (Figure 8C) range from $52^{\circ}$ to $57^{\circ}$, with a typical amplitude of $2^{\circ}$. Assuming a Lambert dependence, a $2^{\circ}$ incidence angle difference would generate a $B S$ contrast of about $20 \log \left(\cos 56^{\circ} / \cos 54^{\circ}\right)=0.4 \mathrm{~dB}$, which is one order of magnitude smaller than the observed $B S$ variations associated with the sediment waves. Furthermore, the average angular response profile $(B S(\theta))$ over the sediment wave field in the Narrow Basin (Figure 9) shows a level of $-5 \mathrm{~dB}$ at nadir, decreasing rapidly to $-25 \mathrm{~dB}$ at $30^{\circ}$ incidence angle, but with a poorly defined specular shape, i.e. with a progressive transition from the specular to the transitory regime. At higher incidence angle, $B S$ decreases slowly to $-33 \mathrm{~dB}$ at $50^{\circ}$. The $B S$ values orthogonal to the sediment wave show fluctuations up to $10 \mathrm{~dB}$ between troughs and crests at all angles. The two observations suggest that the reflectivity contrasts recorded across the sediment waves are controlled by sediment type variations rather than by incidence angle and that, in some situations, analysis of the $B S$ may be 
more efficient for their detection than that of bathymetry. Although some angular dependence is certainly noticeable in the $B S$, its effect is clearly superseded by the sediment type. Consequently bedforms can be detected from backscatter data even when their topographic expression is not measurable.

\subsection{Backscattering Strength Angular Profiles}

The GSAB model was used to generate sets of descriptor values (section 3.3) at key locations in the study area, to explore the relationship between $B S$ and incidence angle on the seafloor. To reduce inter-survey calibration errors, data was only used from the Tan0105 voyage (Figure 6). Tan0105 covers the entire Narrows Basin incorporating a variety of geological features and water depths. The GSAB parameters were generated for eight reference areas selected from the bathymetry and the $B S$ maps (Figure 6). The areas were chosen as homogeneous both in terms of morphology and average $B S$ (Figure 10). Each area typically includes more than 100 complete pings, thus spanning the entire $B S$ angular response and providing a significant average.

The average $B S(\theta)$ generated for the eight reference areas have distinctly different shapes (Figure 11A) generated by the unique seafloor characteristics (interface roughness, impedance and volume scattering) within each region. The GSAB parameters (Table 5) provide a means for further classification of seafloor types from the measured $B S$. 
On the profiles generated from the measured $B S$ (Figure 11A, Table 4), the specular levels range from -23 to $-1 \mathrm{~dB}$. This is larger than the GSAB parameters, where the averaged specular levels ( $A$ in equation 3$)$ range from -13 to $-4 \mathrm{~dB}$ (Figure $11 \mathrm{~B}$, Table 5). The oblique $B S$ levels, at $45^{\circ}$ incidence angle, range from -36 to $-18 \mathrm{~dB}$. The relative specular amplitudes, represented by the contrast between the specular amplitude and the lateral value at $45^{\circ}$, range from $4.5 \mathrm{~dB}$ (Area 4) to $21 \mathrm{~dB}$ (Area 3). The $4.5 \mathrm{~dB}$ relative specular amplitude for Area 4 denotes a weak, or lack of, coherent specular reflection, suggestive of a hard and rough seafloor (Augustin et al., 1997; Hughes Clarke et al., 1997; Le Chenadec et al., 2007). The angular extent of the specular reflection is relatively stable around $5^{\circ}$, suggesting medium to highly scattering interfaces associated with inhomogeneous material. No very narrow specular $\left(<2^{\circ}\right)$ was found comparable to those observed on soft, homogeneous seafloor in the deepsea basins (Augustin et al., 1997). The modelled angular extents of the specular reflection range $3.6^{\circ}$ to $9.5^{\circ}$. In any case, the angular full width of the specular peak cannot be smaller than the sounder beam width $\left(2^{\circ}\right.$ for the EM300) which gives the angle measurement resolution.

Over the eight reference areas, the modelled Lambert references $(C$ in equation 3) range from -31 to $-17 \mathrm{~dB}$ (Table 5). This $14 \mathrm{~dB}$ range indicates important variations in seafloor roughness or sediment volume scattering across the reference areas. The transitory levels for the modelled $B S(E)$ range -21 to $-15 \mathrm{~dB}$, with an average angular extent $(F)$ ranging from $10.1^{\circ}$ 
to $16.6^{\circ}$. These values differ from both the angular extent of the modelled specular reflection $\left(3.6^{\circ}\right.$ to $\left.9.5^{\circ}\right)$ and the angular width of a Lambert's law $\left(45^{\circ}\right)$, confirming the relevance of using a transitory level for accurately modelling the $B S$ angular response.

The increase in $B S$ with grain size noted in previous studies (Briggs et al., 2002; Goff et al., 2000; Jackson and Briggs, 1992) is only perceptible in the Cook Strait data (Tables 5 and 6). In order to further assess the relationship between $B S$ angular profiles and grain size, we selected a small number of samples with average $\varphi$ parameters characteristic of mud, sand and gravel (Tables 3 and 6). We purposefully used an over-simplified model with three end-member characteristics corresponding to soft, medium and rough seafloor. The number of classes is not specifically important as it can be statistically estimated at a later stage for segmentation purposes (Lucieer and Lucieer, 2009). The $B S$ angular response models were established for the three sediment types following the methodology described in section 3.3, for an small area assumed to be representative of a typical grain size as they were selected from homogeneous imagery regions around the samples (Figure 12),. The areas cover between 4 and $20 \mathrm{~km}^{2}$ around the sample locations, which is large compared with the sample size, but are required so that a wide angular range (ideally $0^{\circ}$ to $70^{\circ}$ ) is available to model the full $B S$ angular response. This is mitigated by selecting several areas with characteristic samples for 
gravelly and sandy seafloor (Table 6). The areas for muddy seafloor only include one sample.

The $B S(\theta)$ profiles for gravelly, sandy and muddy seafloors show distinctive shapes (Figure 12) and $A$ to $F$ parameters (Table 5). The muddy seafloor gives the weakest reflectivity on the whole angular range, with a modelled specular level $A=-14 \mathrm{~dB}$ (Table 6). Gravelly and sandy seafloors give similar specular levels of $A=-9 \mathrm{~dB}$. All the specular angular extents have similar values $\left(B=5^{\circ}\right.$ to $\left.6^{\circ}\right)$ the narrowest being for the gravelly seafloor. The Lambert references $(C)$ are $-18,-24$ and $-29 \mathrm{~dB}$ for gravel, sand and mud, respectively. The inter-class spacing (typically $6 \mathrm{~dB}$ ) is well above the separability given by the relative $1 \mathrm{~dB}$ measurement capability of the EM300. Likewise, the modelled transitory levels $(E)$ have distinctive reference level values for gravel $(-18 \mathrm{~dB})$, sand $(-21 \mathrm{~dB})$ and mud $(-25 \mathrm{~dB})$, but the angular extents have comparable values $\left(F=16^{\circ}\right.$ and $18^{\circ}$ ). The angular extents of the specular and transitory levels do not seem to help in deciphering between different grain sizes.

\section{5 - Discussion}

\subsection{Qualitative Interpretation}

The backscatter imagery provides particular fine details that can not be obtained from the bathymetry alone; the imagery can provide additional information on the origin, nature and structure of landforms. The combined use of backscatter and microtopography processing enhance the 
interpretation of fine scale geological and topographical features visible in EM300 multibeam data, such as post- glacial scouring, erosional landforms and carbonated platform concretions $\left(175^{\circ} 37^{\prime} \mathrm{E}-41^{\circ} 38^{\prime} \mathrm{S}, \mathrm{PaB}\right.$ on Figure 5) and canyons floor ( $O C$ on Figure 5). The strong reflectivity on the floor of the Opouawe Canyon suggests gravel deposits indicating active sediment delivery. Relicts of the last glacial transgression are identified on the outer shelf with ripples marks, gravel lags and sediment waves observed in the Campbell Bank (Figure 13). This latter example shows that the backscatter imagery provides even finer details than from the microtopography. An E-W trending, $\sim 50$ m-high scarp is well imaged in the bathymetry and corresponds to strong backscatter on the scarp suggesting a rough seafloor, most likely associated with gravelly material. Immediately north of the fault scarp, N-trending black and white lineaments emphasize seabed features related with contrasting seafloor deposits, but with no topographic expression. By contrast, small depressions visible in the bathymetric image in the NW quadrant of Figure 13 do not exhibit any contrasting backscatter change, suggesting a gentle change in seafloor composition. A similar situation can be seen on Pahaua Bank, where a strongly reflective patch at the shelf break $\left(175^{\circ} 37^{\prime} \mathrm{E}\right.$ $41^{\circ} 38^{\prime} \mathrm{S}$, Figure 5) shows fine details of morphological and geological origin associated with carbonated concretion recognised by Law et al., (2009). 


\subsection{Use of GSAB for Seafloor Characterisation}

While theoretical models of $B S$ angular response may prove useful for characterising the seafloor locally, their benefits for quantitative analysis of regional data sets are limited. There are two main reasons for this situation.

The first reason is that, by definition, accurate physical models are formulated to account for extremely complex processes (e.g., Guillon and Lurton, 2001) requiring a high number of input parameters. This makes inversion results possibly ambiguous as different input parameters may provide similar effects. In the worst case, the inversion may be technically impossible. Moreover, the higher the complexity, the greater the specialisation of a model for a given seafloor type. The second reason is that the measured $B S$ may be dominated by non-anticipated phenomena such as sediment layering, accidental highly-random scatterers, short-scale heterogeneities in the sediment bulk properties or roughness (e.g., Fonseca et al., 2002; Novarini and Caruthers, 1998), or short-term changes of sediment facies. This makes irrelevant the a priori application of a single theoretical model valid only locally on a restrained range of seafloor characteristics; a single physical modelling approach cannot be valid on both, e.g., fine-grain sediments, detritic material, rock structures and vegetal cover

These shortcomings are exacerbated at a regional scale, making it improbable for one dataset to be applicable as a seafloor model over a 
wide area. Therefore the correlation of a set of physical descriptor values with a regional dataset becomes less valuable. This line of reasoning argues in favour of using a more empirical modelling approach focused on a simplified description of the seafloor characteristics, restricted to the identification of major trends but able to cope with strong local variations. In using GSAB, we are attempting to describe physical observations through a restricted set of parameters. The approach is sufficiently versatile to accommodate the diversity of geological environments, while remaining accurate enough for a good-quality correlation to experimental data. Our purpose is not to retrieve quantitative values of seafloor physical or geological properties, but rather to determine descriptor values making it possible to classify the seafloor inside a limited set of classes that may be ground-truthed. Obviously, the accuracy of these descriptors cannot compete with the refinement of the input parameters used in some geoacoustic models (Buchanan, 2005; Buckingham, 2000; Fonseca et al., 2009; Jackson et al., 1986; Stoll, 1985). Rather, the approach is a pragmatic solution to applying the $B S$ signal to enhance geological interpretation.

The gravelly, sandy and muddy GSAB patterns can be used as basic references to provide a first-order interpretation on the average grain size across a large seafloor area. We apply this approach to the Narrows Basin using the GSAB patterns generated in the eight reference areas (Figures 11 and 14). 
At low-incidence angles $\left(0^{\circ}\right.$ to $\left.15^{\circ}\right)$ a close correspondence (e.g. in the lobe angular width) between the mud, sand and gravel GSAB profiles and those of the eight areas is difficult to assess because of the closeness of all profiles.

The correspondence is much clearer around $45^{\circ}$ incidence angle, e.g., for Area 8 where the $B S$ angular profile compares well with the gravel $B S$ profile (Figure 14). This is shown numerically by the parameters $A=-11 \mathrm{~dB}$ and $C=-18 \mathrm{~dB}$ modelled for Area 8 comparing well with $A=-9 \mathrm{~dB}$ and $C=-$ $18 \mathrm{~dB}$ for gravel (Tables 5 and 6). These observations suggest that the continental shelf on the west side of the Narrows Basin likely consists of coarse material. The strongest $B S$ facies in the Narrows Basin is observed in the south basin floor (Area 5) with a modelled specular $A=-4 \mathrm{~dB}$ and Lambert reference $C=-17 \mathrm{~dB}$. The specular is higher than for the gravel profile $(A=-9 \mathrm{~dB})$, suggesting very coarse material in Area 5. A smooth interface between water and soft sediment would have also generated a strong specular, but with a low $B$ and $C$ values, which is not observed in Area 5.

Overall the GSAB profiles for areas 4, 5, and 8 show the highest average $B S$ around the $45^{\circ}$ incidence angle, and hence can be interpreted as representing areas with the coarser material. Areas 6 and 7, along the western flank of the Narrows Basin show very similar characteristics $(A=-$ 7 and $-6 \mathrm{~dB}, C=-20$ and $-19 \mathrm{~dB}$ ) and are intermediate between the sand and gravel profiles at intermediate angles. The specular levels for the gravel 
and sand are identical $(A=-9 \mathrm{~dB})$ and hence not discriminating. However, the three $B S$ level parameters $(A, C$, and $E)$ are higher for Area 6 than for Area 7, suggesting coarser deposits in the south than in the central basin wall. Interestingly, Area 3 is largely dominated by sediment waves and presents the weakest $B S$ response, with Lambert reference $C=-31 \mathrm{~dB}$ and specular $A=-10 \mathrm{~dB}$. In details, the $B S$ varies across dunes and sediment waves, whereas on a regional scale the homogenised reflectivity suggests on the average fine sandy-mud material on the floor of the Narrows Basin. The angular extent of the specular reflection $(B)$ is an indicator of the interface roughness. The maximum and minimum values for $B$ are observed for areas $5\left(9.5^{\circ}\right)$ and $1\left(3.6^{\circ}\right)$, respectively (Table 5). These are consistent with coarse to very coarse material including pebbles and boulders retrieved from Area 5, whereas fine sand was retrieved from Area 1. Area s 4 and 5 show contrasting values for the specular ( -13 and $-4 \mathrm{~dB}$, respectively), and a marked difference in the angular extent of the specular $\left(4.8^{\circ}\right.$ and $\left.9.5^{\circ}\right)$ which suggests that the floor of the Narrows Basin (Area 5) has a substantially higher water-sediment impedance contrast and interface roughness than the small basin on the continental shelf (Area 4). The similar Lambert reference $(C=-17 \mathrm{~dB})$ for areas 4 and 5 indicates similar sediment characteristics in terms of volume homogeneity, likely to be coarse sand or gravelly sand. The 43 samples in Area 5 (Table 5) confirm the presence of coarser material than in Area 4. Overall, however, the $B$ 
may too strongly linked with the vertical beam width to generate an accurate enough descriptor.

The data also indicate that the transitory level $(E)$ may be characteristic of large-scale seafloor roughness, as when $E$ is high and contrasting with $A$ and $C$ as in areas $3(E=-21 \mathrm{~dB})$ the rugosity is a particular case as it includes sediment waves. We infer that the transitory ( $E$ and $F$ ) components are indicators of a scale rugosity in the order of magnitude ( $100-500 \mathrm{~m})$ of the sediment wave wavelength, rather that at the scale of local slope, in relation with the sounder signal footprint to be considered in the specular behaviour modelled by the facet theory (Brekhovskikh \& Lysanov, 2002).

\subsection{Quantitative BS for geological mapping}

From the eight reference areas in Cook Strait, we show that the six GSAB parameters can be used to quantitatively characterise $B S$ for a variety of environments. However, these data are still too complex to develop a reflectivity map at a regional scale. We propose to use the $B S$ at $45^{\circ}$ incidence angle (noted $B S_{45}$ ) as a parameter representing the overall $B S$ behaviour. In conventional MBES surveys, a swath width (aperture of ca. $60^{\circ}$ ) covers approximately four times the water depth, and the $45^{\circ}$ incidence angle represents the median value on both sides of the specular. For instance, the minimum and maximum calibrated $B S$ values acquired (all angles put together) during the Tan0105 survey are -55 and $18 \mathrm{~dB}$, with a mean of $-25 \mathrm{~dB}$ (Table 4). The abnormally high $B S$ values at 
specular level are due to the presence of a coherent reflection process superseding the backscattered return and are unreliable. At grazing angles $\left(68^{\circ}-72^{\circ}\right)$, the $B S$ is irregular due to strong angle dependence and poor signal-to-noise ratio and are not always validated. $B S_{45}$ is therefore most suitable to represent the $B S$ in one synthetic value.

The backscatter map, normalised at the $B S_{45}$ value for survey Tan0105 (Figure 6B) shows clearly separated regions; sufficiently homogeneous when considered individually ( $B S_{45}$ dynamics is $6 \mathrm{~dB}$ over the sediment waves). The contrast between the reference areas is sufficient for a fairly accurate visual classification $\left(B S_{45}\right.$ typical values of $-34 \mathrm{~dB}$ and $-20 \mathrm{~dB}$ in areas 3 and 5, respectively Table 5).

$B S_{45}$ is proving to be a robust single parameter for application to habitat mapping. At a regional scale in Cook Strait $B S_{45}$ can discriminate distinct environments, which have different geological or micro-topographic properties. It therefore provides a tool for geological interpretation. The use of $B S_{45}$ as a reference value is of course conditioned by the availability of the sounder calibration in absolute level. This will have to be validated from further studies, but we suggest that $B S_{45}$ be used systematically for building compensated sonar images where one reflectivity value has to stand for one homogeneous seafloor facies. Such an approach would have the significant benefit of providing qualitative images comparable globally, thus enabling comparison from different regions. $B S_{45}$ maps, however, still have limited classifying power other than relative contrast, 
since the information inherent to the angle response has disappeared. This is exacerbated if the sounder absolute calibration is not available; then only the contrast between various responses can be exploited.

We propose the use the relative specular level with regard to the oblique regime average level, given by $A-C$ or Specular-To-Oblique Contrast (STOC), as an indicator of both the impedance contrast and the interface roughness. STOC, as $B, D, F$ and $(E-C)$, have the significant advantage of being independent from the sounder absolute-level calibration, and can therefore be used globally. The STOC parameter for the eight representative areas in the Narrows Basin (Table 5, Figure 15) ranges from $4.5 \mathrm{~dB}$ to $21 \mathrm{~dB}$, i.e. a total dynamic of $16.5 \mathrm{~dB}$. A scatter plot of STOC vs. $C$ for the eight reference areas (Figure 15) suggests that these parameters may provide some classifying potential as they show a good inter-class separation. This is promising as class separation is a requisite for segmentation and classification algorithms to run effectively (e.g., Lucieer and Lucieer, 2009). Enabling robust class separation from $B S$ measurements increases the rationale of using $B S$ in habitat mapping.

\section{CONCLusion}

The development of a quantitative automated seafloor mapping tool has been a priority for geologists since acoustics was first used to map the ocean floor. In this paper we have refined the $B S$ signal interpretation and isolated some of its complex relationships with the substrate. 
It is well established that $B S$ is controlled by the sediment grain size, the surficial heterogeneity and the small-scale topography, and therefore relates to substrate composition and roughness. Absolute amplitude calibration is required for quantitative analysis whereas statistical compensation of the $B S$ angular response is a prerequisite for qualitative interpretation. Both the calibrated and statistically compensated data are required for a complete quantitative and qualitative interpretation of the seafloor composition and interface characteristics. The $B S$ angular response also provides insights into the seafloor primary sedimentary (grain size) and geomorphological (seafloor roughness) properties at both local and regional scales.

Qualitatively, the backscatter data in the Cook Strait region are characterised by weak, homogeneous reflectivity patterns over the continental shelf and deep Hikurangi Trough indicating fine sediment, likely mud or sandy mud, and strong reflectivity on the canyons floors indicating gravel deposits and active sediment delivery. Strongly reflective spots on the continental shelf highlights carbonate concretions and erosional landforms.

Backscatter imagery and bathymetry data together provide a tool for enhanced interpretation of fine scale structures that may not necessarily have geomorphic relief but have distinctive surface textures or roughness. In the Narrows Basin, the backscatter pattern of strong reflectivity on sediment wave's troughs and weak reflectivity on the crests indicates that 
the $B S$ variations across the sediment waves are associated with gravelly deposits at their base and fine sandy deposits at their top. In some areas, the backscatter data display a quasi-periodical structure emphasising fine sediment waves otherwise undetected in multibeam bathymetry.

Modelling of the backscatter signal as a function of the incidence angle enables us to provide quantitative information on the seafloor. A Generic Seafloor Acoustic Backscatter (GSAB) improved model is used to define six physically significant parameters $(A$ to $F)$ for a number of homogeneous and distinctive areas in the Cook Strait. The six quantitative parameters $(A$ to $F)$ for muddy, sandy and gravelly seafloors are used as reference to provide information on the seafloor composition.

We propose to use two parameters to simplify the management of the multi-parameter models, and to define a classification of the average seafloor characteristic adapted to the regional scale relevant for many habitat mapping studies: the $B S$ value acquired at $45^{\circ}\left(B S_{45}\right)$ incidence angle as a stable indicator of the interface sediment type, usable either as an absolute descriptor or as a comparison tool, depending on the sounder calibration status; and the specular-to-oblique (STOC) contrast which provides an indication of the behaviour of interface roughness through its impact on the specular reflection. STOC has the added advantage of being independent from absolute data level calibration. 


\section{ACKNOWLEDGMENTS}

This project was funded by the New Zealand Foundation for Research Science and Technology (FRST) through their programme Consequence of Earth Ocean-Change (C01X0702). Thanks go to Hugues de Longevialle, Ifremer's Direction of International Relations for supporting this NIWA-IFREMER collaboration. Sediment analyses were performed at NIWA by Lisa Northcote and Melanie Herrmann. Joshu Mountjoy (NIWA) commented on an early version of the manuscript, and Richard Pickrill (Geological Survey Canada) commented on the reviewed version. Figures were generated using the Sonarscope ${ }^{\circledR}$ and GMT software. 


\section{REFERENCES}

Anderson, J.T., Van Holliday, D., Kloser, R., Reid, D.G. and Simard, Y., 2008. Acoustic seabed classification: Current practice and future directions. ICES Journal of Marine Science, 65(6): 1004-1011. doi.10.1093/icesjms/fsn061

Augustin, J.M., Dugelay, S., Lurton, X. and Voisset, M., 1997. Applications of an image segmentation technique to multibeam echo-sounder data, OCEANS apos'97. MTS/IEEE Conference Proceedings, Halifax, NS, Canada, pp. 1365-1369.

Augustin, J.M., Le Suave, R., Lurton, X., Voisset, M., Dugelay, S. and Satra, C., 1996. Contribution of the multibeam acoustic imagery to the exploration of the seabottom: Examples of SOPACMAPS 3 and ZoNéCo 1 cruises. Marine Geophysical Researches, 18(2-4): 459-486

Augustin, J.M. and Lurton, X., 2005. Image amplitude calibration and processing for seafloor mapping sonars, Oceans 2005 - Europe, pp. 698 - 701.

Barnes, P.M., Lamarche, G., Bialas, J., Henrys, S., Pecher, I., Netzeband, G., Greinert, J., Mountjoy, J.J., Pedley, K. and Crutchley, G., 2009. Tectonic and geological framework for gas hydrates and cold seeps on the Hikurangi subduction margin, New Zealand. Marine Geology, in press. doi.10.1016/j.margeo.2009.03.012

Blott, S. and Pye, K., 2000. GRADISTAT: a grain size distribution and statistics package for the analysis of unconsolidated sediments. Earth Surface Processes and Landforms, 26(11): 1237-1248. doi.10.1002/esp.261

Brekhovskikh, L. and Lysanov, Y., 1982 Fundamentals of ocean acoustics, in. Springer Series in Electrophysics, Felsen, L, (Ed.), Vol.8, Springer-Verlag, Berlin Heidelberg New York, 249p. 
Briggs, K.B., Williams, K.L., Jackson, D.R., Jones, C.D., Ivakin, A.N. and Orsi, T.H., 2002. Fine-scale sedimentary structure: Implications for acoustic remote sensing. Marine Geology, 182(1-2): 141-159

Buchanan, J.L., 2005. An Assessment of the Biot-Stoll Model of a Poroelastic Seabed. NRL/MR/7140--05-8885, Naval Research Laboratory, Washington, DC 20375-5320. $81 \mathrm{p}$.

Buckingham, M.J., 2000. Wave propagation, stress relaxation, and grain-to-grain shearing in saturated unconsolidated sediments. Journal Acoustical Society of America, 108(6): 2796-2815

Carter, L., 1992. Acoustical characterisation of seafloor sediments and its relationship to active sedimentary processes in Cook Strait, New Zealand. New Zealand Journal of Geology and Geophysics, 35: 289-300

de Moustier, C., 1986. Beyond bathymetry: mapping acoustic backscattering from the deep seafloor with Sea Beam. Journal Acoustical Society of America, 79(2): 316-331

Ehrhold, A., Hamon, D. and Guillaumont, B., 2006. The REBENT monitoring network, a spatially integrated, acoustic approach to surveying nearshore macrobenthic habitats: application to the Bay of Concarneau (South Brittany, France). ICES Journal of Marine Science, 63(9): 1604-1615. doi.10.1016/j.icesjms.2006.06.010

Fonseca, L., Brown, C., Calder, B., Mayer, L. and Rzhanov, Y., 2009. Angular range analysis of acoustic themes from Stanton Banks Ireland: A link between visual interpretation and multibeam echosounder angular signatures. Applied Acoustics, 70(10): 1298-1304. doi.10.1016/j.apacoust.2008.09.008 
Fonseca, L., Mayer, L.A., Orange, D. and Driscoll, N.W., 2002. The high-Frequency backscattering angular response of gassy sediments: model/data comparison from the Eel River margin, California Journal of Acoustical Society of America, 111(6): 26212631

Foote, K.G. 1980. Importance of the swimbladder in acoustic scattering by fish: A comparison of gadoid and mackerel target strengths. Journal Acoustical Society of America 67 (6): 2084-2089.

Foote, K.G., Chu, D., Hammmar, T.R., Baldwin, K.C., Mayer, L.A., Hufnagle, L.C.Jr and Jech, J.M. 2005. Protocols for calibrating multibeam sonar. Journal Acoustical Society of America, 117(4): 2013-2027

Goff, J.A., Olson, H.C. and Duncan, C.S., 2000. Correlation of side-scan backscatter intensity with grain-size distribution of shelf sediments, New Jersey margin. GeoMarine Letters, 20(1): 43-49

Guillon, L. and Lurton, X., 2001. Backscattering from buried sediment layers: The equivalent input backscattering strength model. Journal Acoustical Society of America, 109(1): 122-132

Hellequin, L., Boucher, J.M. and Lurton, X., 2003. Processing of high-frequency multibeam echo sounder data for seafloor characterization. IEEE Journal of Oceanic Engineering, 28(1): 78-89. doi.10.1109/JOE.2002.808205

Hellequin, L., Lurton, X. and Augustin, J.M., 1997. Postprocessing and signal corrections for multibeam echosounder images, Oceans Conference Record (IEEE), pp. 23-26. 
Hicks, D.M. and Shankar, U., 2003. Sediment yield from New Zealand rivers. NIWA chart, Miscellaneous series N.79. National Institute of Water and Atmospheric Research, Wellington, NZ.

Hughes Clarke, J.E., Danforth, B.W. and Valentine, P., 1997. Areal seabed classification using backscatter angular response at $95 \mathrm{kHz}$, High Frequency Acoustics in Shallow Water, NATO SACLANT Undersea Research Centre, Lerici, Italy.

Hughes Clarke, J.E., Mayer, L.A. and Wells, D.E., 1996. Shallow-water imaging multibeam sonars: A new tool for investigating seafloor processes in the coastal zone and on the continental shelf. Marine Geophysical Researches, 18(6): 607-629

Jackson, D.R. and Briggs, K.B., 1992. High-frequency bottom backscattering: Roughness versus sediment volume scattering. Journal of the Acoustical Society of America, 92(2 I): 962-977

Jackson, D.R., Ishimaru, A. and Winebrenner, D.P., 1986. Application of the composite roughness model to high frequency bottom backscattering. Journal Acoustical Society of America, 79(5): 1410-1422

Kongsberg, 1997, EM300 operator manual, N.160719/C, Kongsberg Simrad AS Horten, Norway, 398p.

Law, C.S., Nodder, S.D., Mountjoy, J., Marriner, A., Orpin, A., Pilditch, C.A., Franz, P. and Thompson, K., 2009. Geological, hydrodynamic and biogeochemical variability of a New Zealand deep-water methane cold seep during an integrated three year time-series study. Marine Geology. doi.10.1016/j.margeo.2009.06.018

Le Chenadec, G. and Boucher, J.-M., 2005. Sonar Image Segmentation using the Angular Dependence of Backscattering Distributions, Proceedings IEEE Oceans Europe 2005. 
Le Chenadec, G., Boucher, J.-M. and Lurton, X., 2007. Angular Dependence of KDistributed Sonar Data. IEEE Transactions on Geoscience and Remote Sensing, 45(5): 1224-1235. doi.10.1109/TGRS.2006.888454

Le Gonidec, Y., Lamarche, G. and Wright, I.C., 2003. Inhomogeneous Substrate Analysis Using EM300 Backscatter Imagery. Marine Geophysical Researches, 24: 311-327. doi.10.1007/s11001-004-1945-9

Lewis, K.B., Carter, L. and Davey, F.J., 1994. The opening of Cook Strait: interglacial tidal scour and aligning basins at a subduction to transform plate edge. Marine Geology, 116(3/4): 293-312

Lucieer, V. and Lucieer, A., 2009. Fuzzy clustering for seafloor classification. Marine Geology, 264(3-4): 230-241. doi.10.1016/j.margeo.2009.06.006

Lurton, X., 2003a. Underwater Acoustics. An Introduction. Geophysical Sciences. Jointly published Springer Praxis Books \& Praxis Publishing, UK, 356 pp.

Lurton, X., 2003b. Theoretical modelling of acoustical measurement accuracy for swath bathymetric sonar. International Hydrographic Review, 4(2): 24-37

Lurton X., Augustin J.M., Dugelay S., Hellequin L., Voisset M., 1997. Shallow-water seafloor characterization for high-frequency multibeam echosounder: image segmentation using angular backscatter, Proceedings of SACLANTCEN Conference CP-45, High Frequency Shallow Water Acoustics, Pace, N. (Ed.)

Maître, H.,, 2001, Traitement des images de radar à synthèse d'ouverture. Paris: Hermes Sciences Europe Ltd, 351pp.

McRea Jr, J.E., Greene, H.G., O'Connell, V.M. and Wakefield, W.W., 1999. Mapping marine habitats with high resolution sidescan sonar. Oceanologica Acta, 22(6): 679686 
Medialdea, T., Somoza, L., León, R., Farrán, M., Ercilla, G., Maestro, A., Casas, D., Llave, E., Hernández-Molina, F.J., Fernández-Puga, M.C. and Alonso, B., 2008. Multibeam backscatter as a tool for sea-floor characterization and identification of oil spills in the Galicia Bank. Marine Geology, 249(1-2): 93-107. doi.10.1016/j.margeo.2007.09.007

Mountjoy, J.J., Barnes, P.M. and Pettinga, J.R., 2009. Morphostructure and evolution of submarine canyons across an active margin: Cook Strait sector of the Hikurangi Margin, New Zealand. Marine Geology, 260(1-4): 45-68. doi.10.1016/j.margeo.2009.01.006

Mourad, P.D. and Jackson, D.R., 1989. High Frequency Sonar Equation Models For Bottom Backscatter And Forward Loss, IEEE OCEANS '89 Proceedings, pp. 11681175 .

Mulhearn, P.J., 2000. Modelling Acoustic Backscatter from Near-Normal Incidence Echosounders - Sensitivity Analysis of the Jackson Model, DSTO-TN-0304. DSTO Aeronautical and Maritime Research Laboratory, Melbourne Victoria 3001 Australia, $36 \mathrm{pp}$.

Novarini, J.C. and Caruthers, J.W., 1998. A simplified approach to backscattering from a rough seafloor with sediment inhomogeneities. IEEE Journal of Oceanic Engineering, 23(3): 157-166

Pratson, L.F. and Edwards, M.H., 1996. Introduction to Advances in Seafloor Mapping Using Sidescan Sonar and Multibeam Bathymetry Data. Marine Geophysical Researches, 18: 601-605

Ryan, W.B.F. and Flood, R.D., 1996. Side-looking sonar backscatter response at dual frequencies. Marine Geophysical Researches, 18(6): 689-705 
Stoll, R.D., 1985. Marine sediment acoustics. Journal of the Acoustical Society of America, 77(5): 1789-1799

Van Dissen, R.J. and Berryman, K.R., 1996. Surface-rupture earthquakes over the last ca, 1000 years in the Wellington region, New Zealand, and implications for ground shaking hazard. Journal of Geophysical Research, 101(B3): 5999-6019

Wright, D.J. and Heyman, W.D., 2008. Introduction to the Special Issue: Marine and Coastal GIS for Geomorphology, Habitat Mapping, and Marine Reserves. Marine Geodesy, 31(4): 223 - 230. doi.10.1080/01490410802466306 


\section{Figure CAPTIONS}

Figure 1 - Bathymetry of Cook Strait gridded at $25 \mathrm{~m}$, and compiled from MBES surveys. The intense colour DTM is $N B$ : Nicholson Bank; $N C$ : Nicholson Canyon, $W C$ : Wairarapa Canyon; $C k$ : Cook Strait Canyon, $P B$ : Palliser Bank; $P C$ : Palliser Canyon; OR: Opouawe Ridge; $O C$ : Opouawe Canyon; PaB; Pahaua Bank; PaC; Pahaua Canyon. Insert: The Pacific-Australia (PAC-AUS) plate boundary (teeth line) and principal faults.

Figure 2 - Calibration of the backscatter data for a 3-sector configuration sounder, undertaken using gain functions provided by the manufacturer (dotted line in $A$ ) and re-calculated using the SonarScope ${ }^{\circledR}$ software (bold line in $A$ ). B) Backscatter angular profiles generated with manufacturer (dotted line) and re-calculated (bold line) gain functions. Datagrams with manufacturer $(C)$ and re-calculated $(D)$ calibrations. Arrows indicate sector transitions.

Figure 3 - A) Calibrated reflectivity in the Narrows Basin. The backscattering strength $(B S)$ includes the full extent of the specular echo and the lateral decrease with angle has been compensated by Lambert's law. B) Fully processed backscatter reflectivity. The compensation of the backscatter was undertaken by applying a gain function as shown in (C). An $11 \times 11$ pixel speckle filter is also applied to the data. The compensated data have lost their absolute reference level (see text). C) The statistical 
compensation is performed by subtracting a bias value (thin grey) to the measured calibrated backscatter (thick grey) and provides the compensated angular response.

Figure 4 - Modelling of the $B S$ angular response using the Generic Seafloor Acoustic Backscatter (GSAB) model. The parameterised $B S$ angular function model (thick grey) fits the averaged measured $B S$ values for a selected number of pings in a given area (crosses) and is the sum of two Gaussian functions for the specular reflection (short black dash) and transitory level (long dark grey dash) and a Lambert law (dark grey) for high incidence angles. The three curves are defined using the 6 parameters $A$ to $F$ in the equation $B S(\theta)=10 \log \left[A \cdot \exp \left(-\theta^{2} / 2 B^{2}\right)+C \cdot \cos ^{D} \theta+E \cdot \exp (-\right.$ $\left.\left.\theta^{2} / 2 F^{2}\right)\right]$

Figure 5 - $\quad$ Fully processed (calibrated and compensated) backscatter imagery of Cook Strait (A). Note that strong intensity shows in white. Thick dash lines indicate the boundaries of individual datasets for which the survey number is indicated in bold. $N B$ : Narrow Basin; $N C$ : Nicholson Canyon; $B B$ : Booboo Fault Scarp; $O C$ : Opouawe Canyon; $P B$ : Palliser Bank; PaB: Pahaua Bank. See Figure 1 for full caption. (B) 3-D oblique view of the sediment waves in the Narrows Basin; looking to the NE, $(P a B)$ : Calibrated and compensated backscatter imagery of carbonated concretions on the Pahaua Bank. Main figure and inserts generated using 
the Sonarscope ${ }^{\circledR}$ software. Frames indicate the locations of subsequent figures.

Figure 6 - Seafloor morphology (top) and fully processed backscatter imagery (bottom) in the Narrows Basin. The backscatter imagery is compensated using the $B S$ intensity at $45^{\circ}$ incidence angle $\left(B S_{45}\right)$. Eight reference areas (numbered) were identified from the bathymetry and backscatter homogeneity for generating average $B S$ angular profiles (Figure 11, Table 5).

Figure 7 - Bathymetric, calibrated $B S$, compensated backscatter and incidence angle profiles (from top to bottom) across a sediment wave field in central Cook Strait (location on small backscatter map). Profiles generated using a 5-m grid.

Figure 8 - Compensated backscatter (A), bathymetric $(B)$ and incidence angles $(C)$ profiles across a sediment wave field in central Cook Strait. The sediment waves are only detected using reflectivity, whereas the bathymetry does not show any morphological sediment wave pattern. The incidence angles vary little, which demonstrates that the variation in $B S$ is likely due to the geology and microtopography.

Figure 9 - $\quad$ Average angular backscatter strength $(B S)$ profiles (thick grey) over a sand wave field. The standard deviation (dotted lines) indicates the backscatter distribution variation with the incidence angle. 
Inserts show the $B S$ profiles at four beam incident angles $\left(0^{\circ}, 25^{\circ}, 45^{\circ}\right.$, $60^{\circ}$ ) over $\sim 600$ pings.

Figure 10 - Average $B S$ angular responses for reference areas 2 and 5 (Figure 6) with error bars indicating standard deviation computed for 5degree angle bins.

Figure 11 - $B S$ angular profiles of the calibrated backscatter $(A)$ and generated using the Generic Seafloor Acoustic Backscatter (GSAB) model $(B)$ as developed in this study (see text) for the eight reference areas in central Cook Strait (Figure 6). Parameters $A$ to $F$ generated by the models in Table 5.

Figure 12 - Generic Seafloor Acoustic Backscatter (GSAB) models for characteristic samples of gravelly, sandy and muddy seafloors defined from grain size analysis (Table 3). Thick grey: $B S$ angular function model of the averaged measured values (dots). Dash grey lines: parameterised profile used for the GABS (figure 4; section 3.3). A model for mud with underlying compacted sediments is superimposed on the model for muddy seafloor. See Figure 5 for sample locations. Samples average compositions (Table 6) are indicated as percentage of gravel, sand and mud.

Figure 13 - Morphological scarp associated with the active Booboo Fault and seafloor erosional landforms over the Campbell Bank. (A) Multibeam bathymetry, generated from the log of the bathymetry with 
north illumination; (B) Compensated backscatter reflectivity. Location on Figure 5 .

Figure 14 - Modelled $B S$ angular profiles for the eight representative areas (Figure 6) in the Narrows Basin superimposed on the gravel, sand and mud modelled $B S$ angular profiles. Only the positive incidence angles are represented on the figure as the models are symmetrical (Table 5).

Figure 15 - Scatter plot of $A-C$ vs. $B S_{45}$. Error bars are indicated based on standard deviation on $B S$ measurements as the GSAB model does not provide errors. 


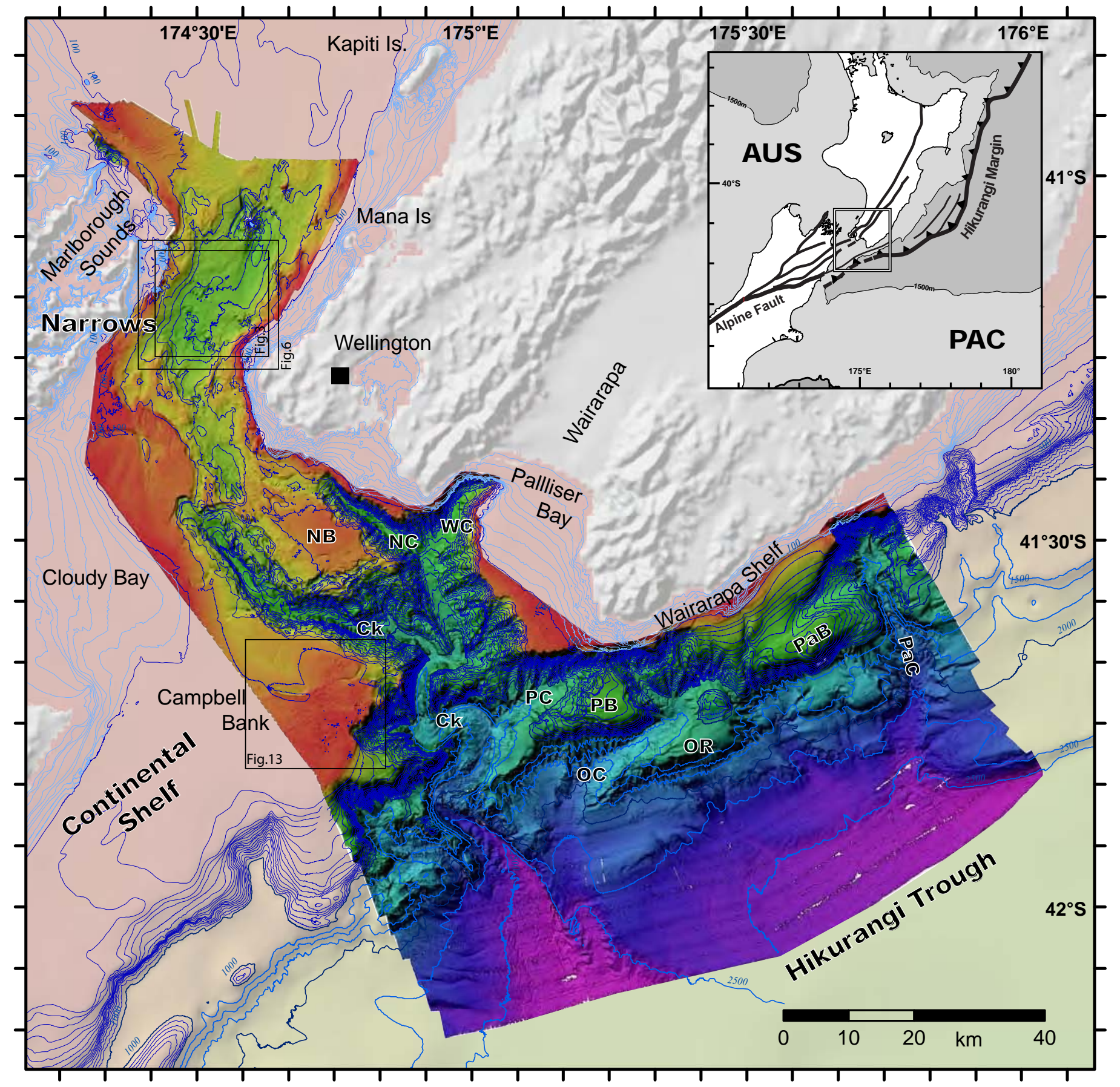



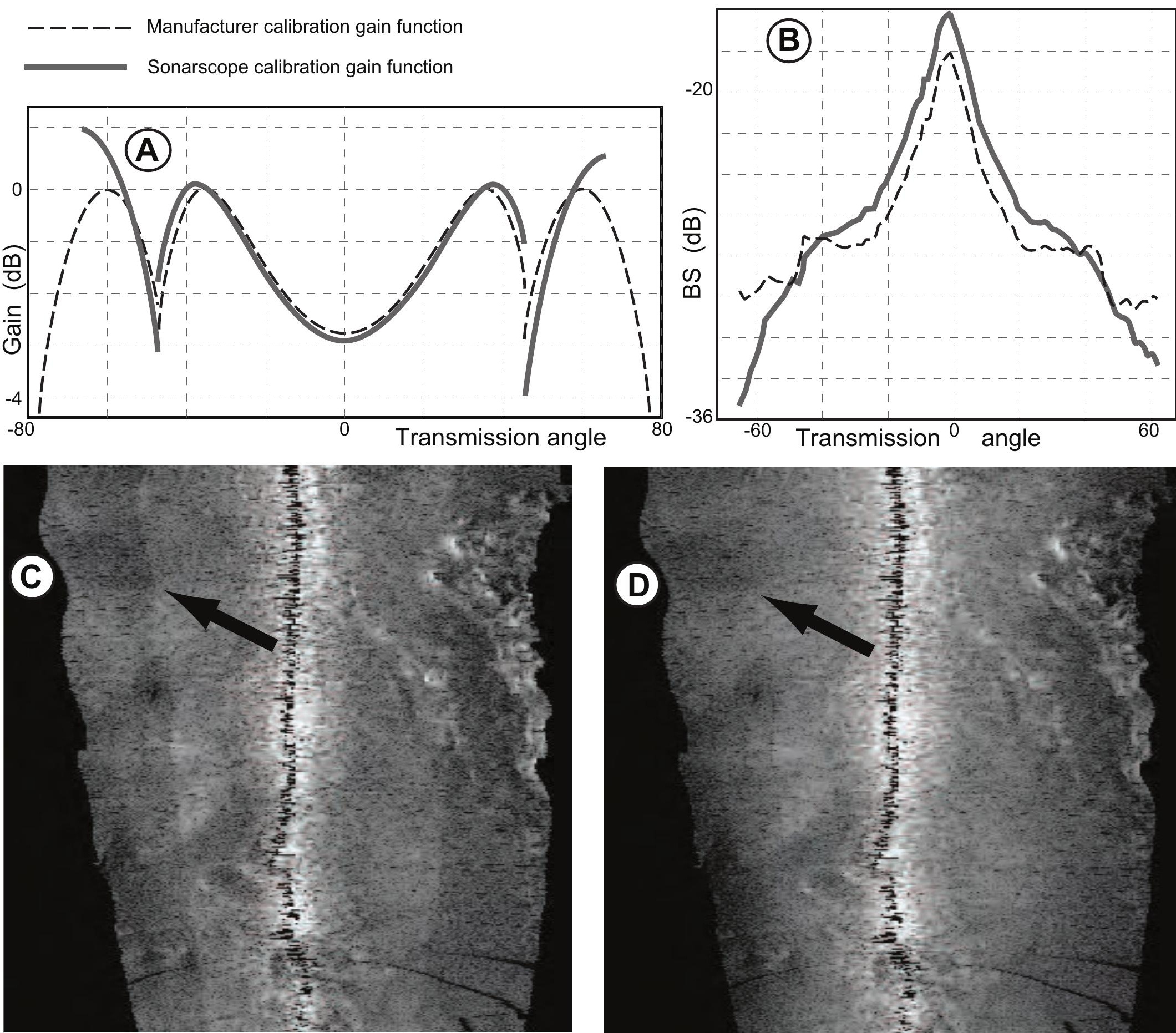


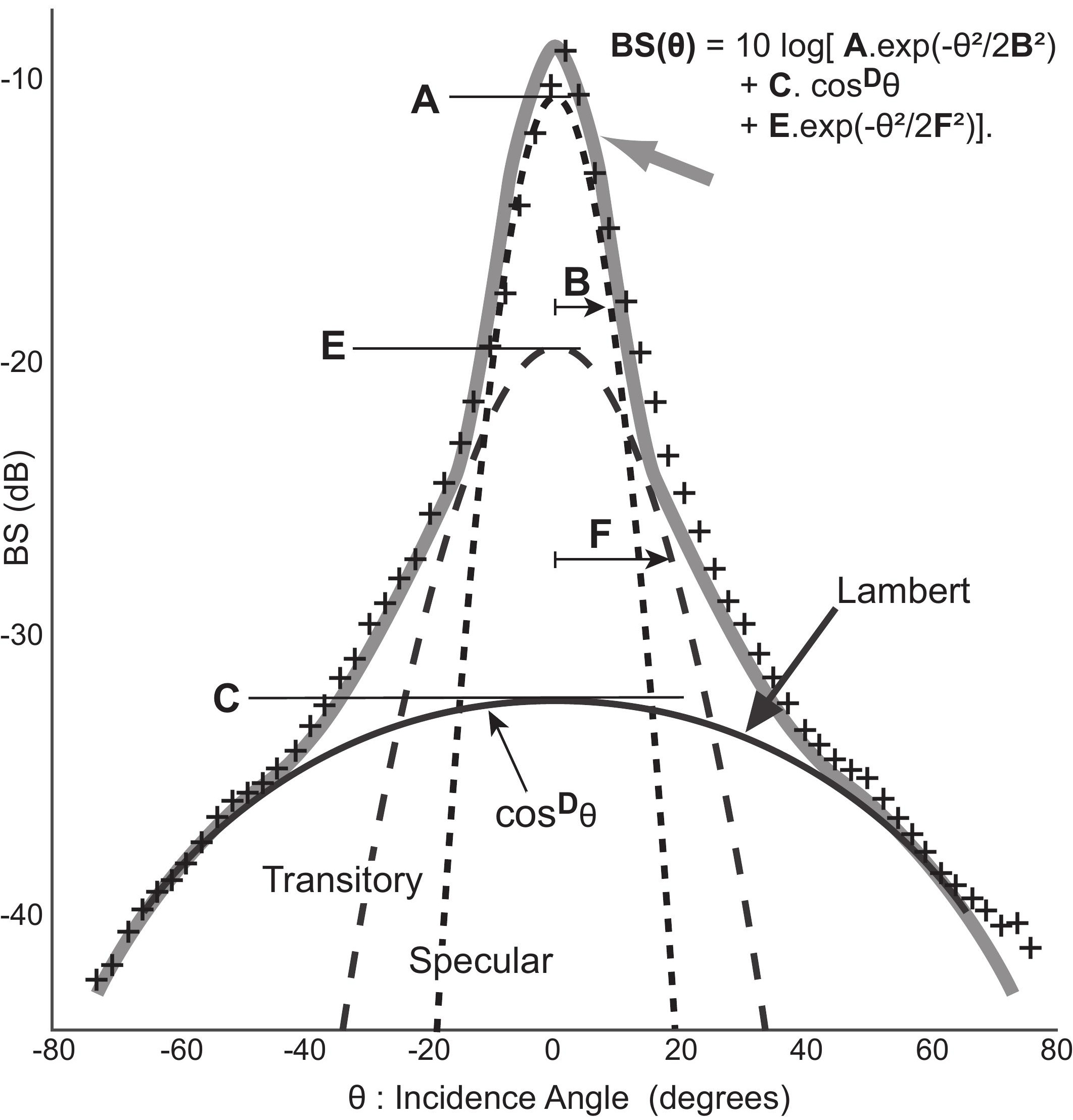



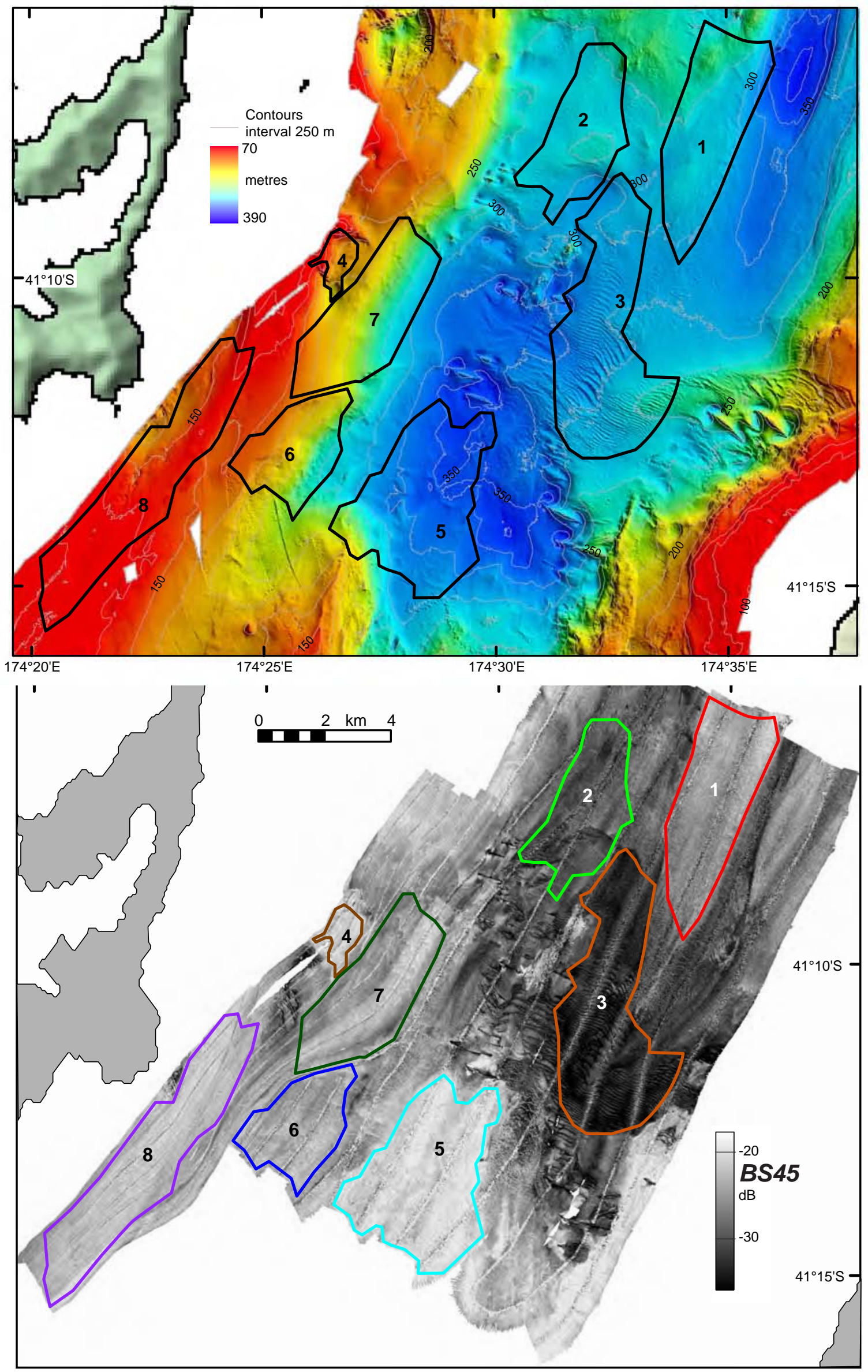
Figure 8

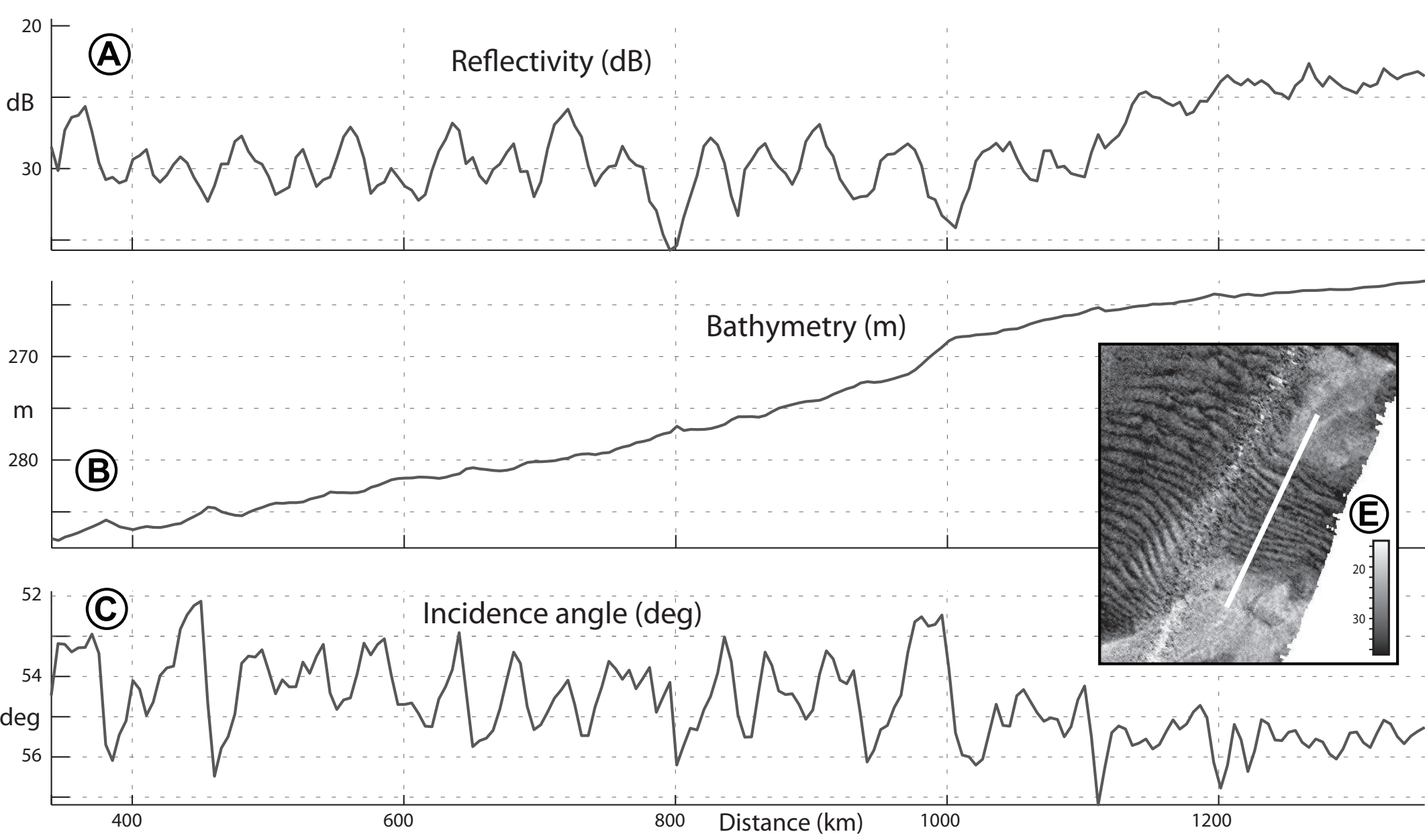


Figure 9

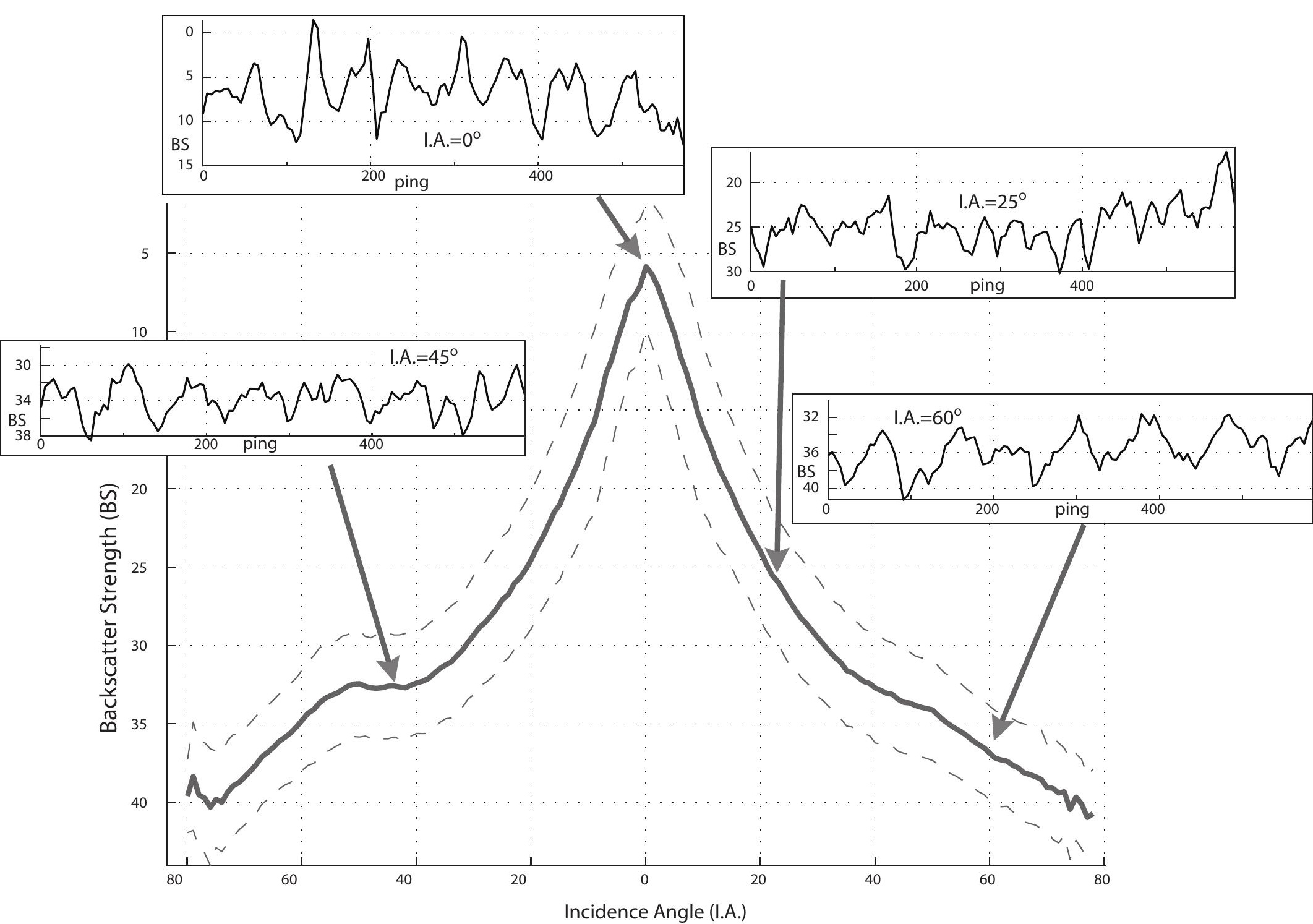


Figure 10

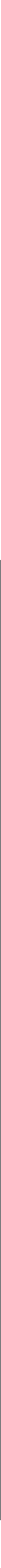

.

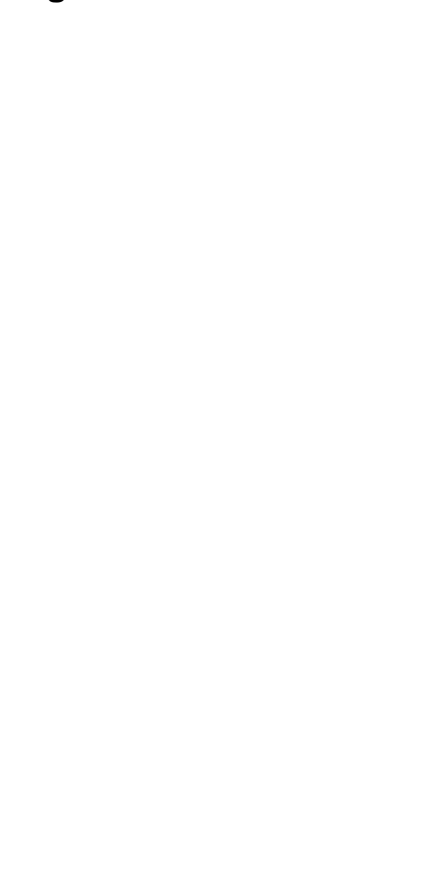


Ejgure 11
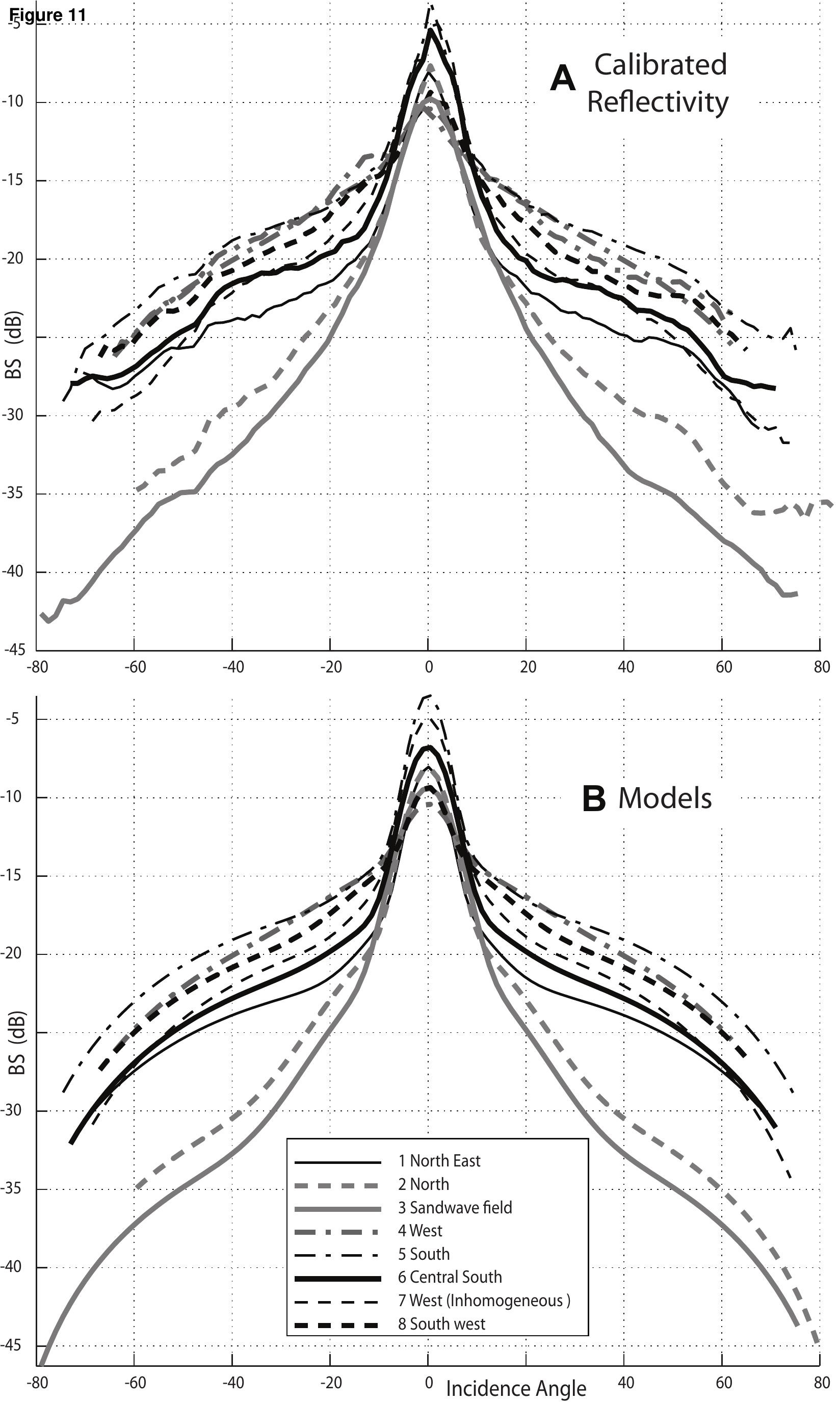


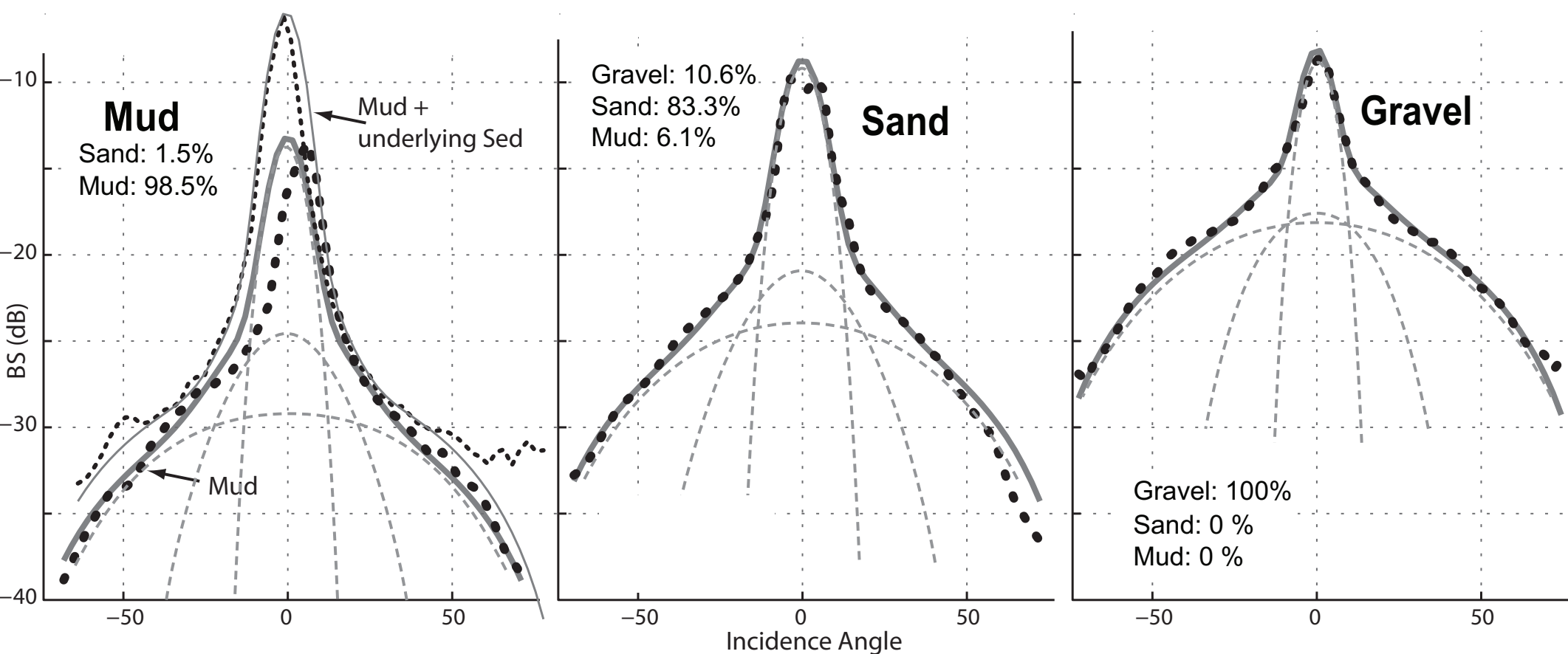


Figure 13 (web color, B\&W print)
Click here to download high resolution image
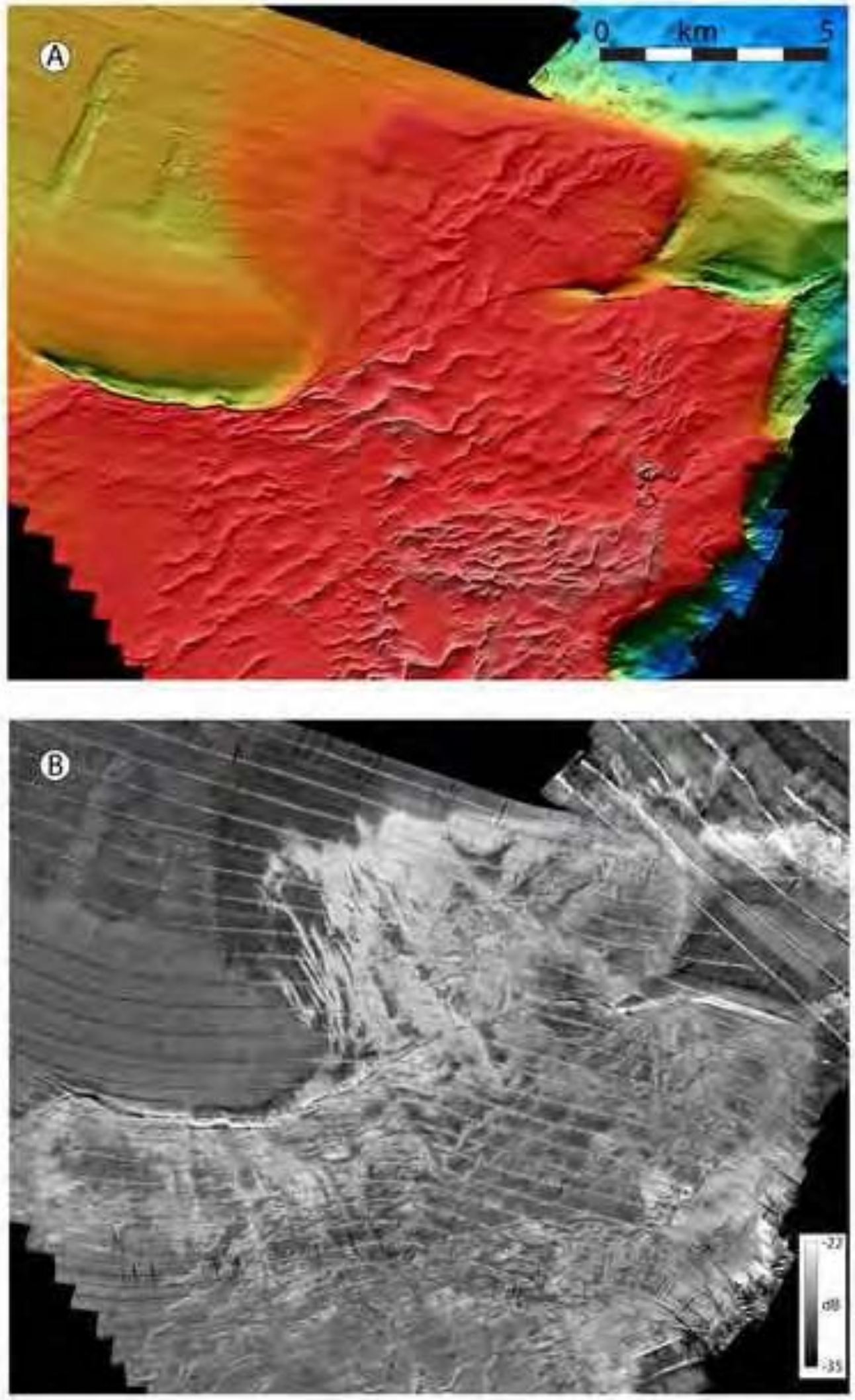


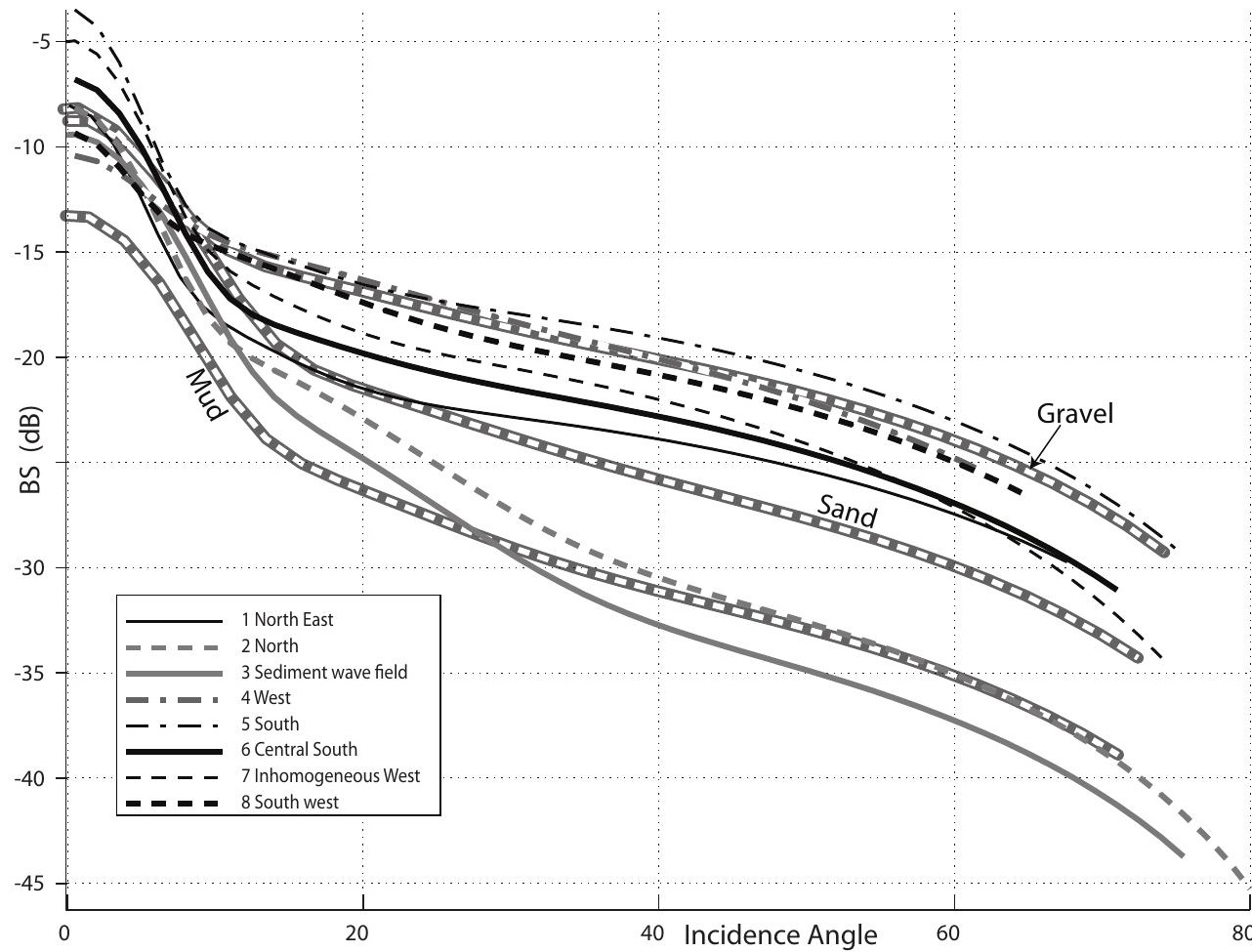

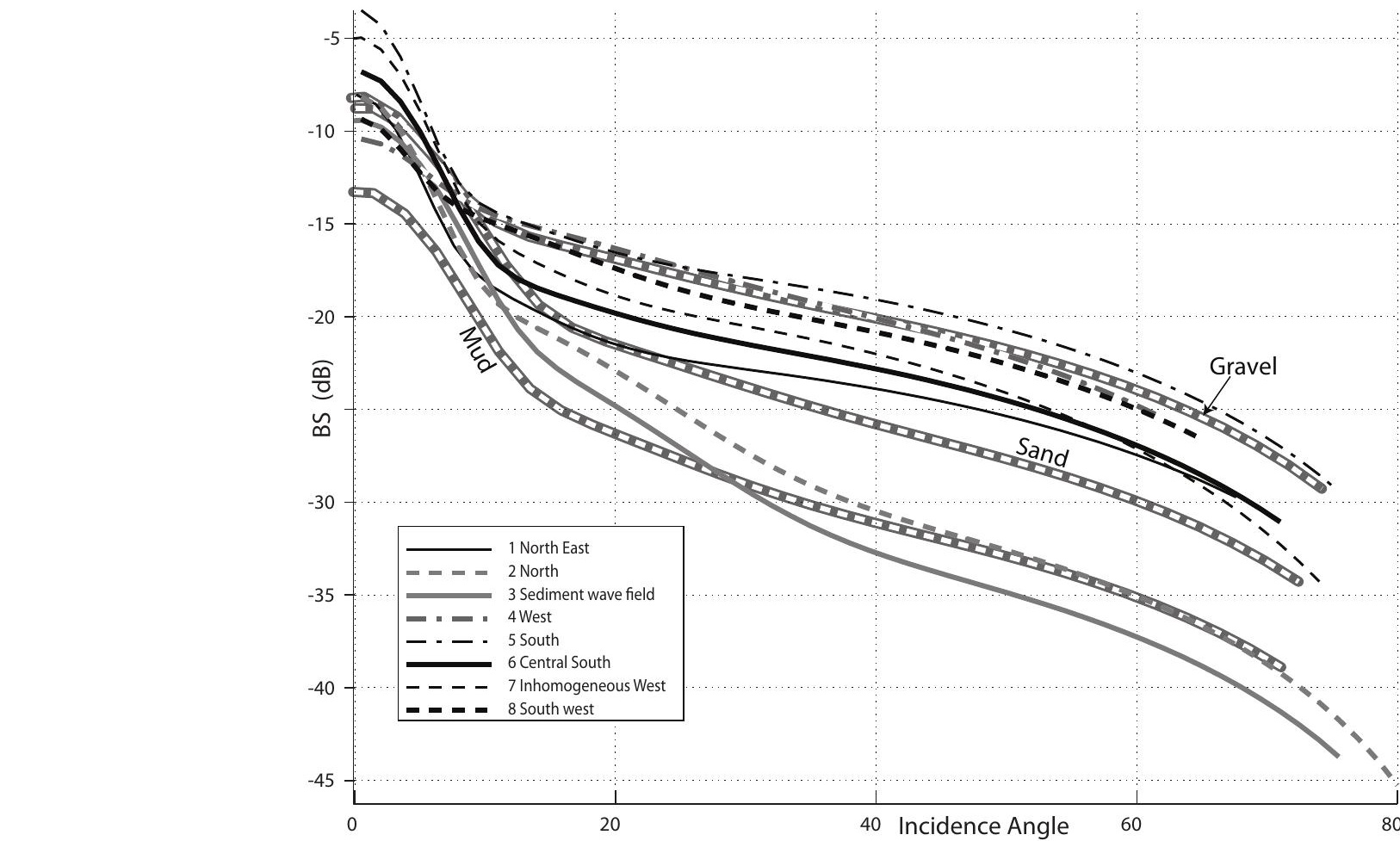


Figure 15

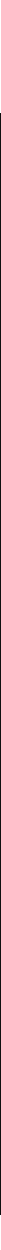

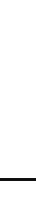




\section{TABLES}

Table 1: R.V Tangaroa surveys in Cook Strait for EM300 acquisition (Figures 2 and 5)

\begin{tabular}{|l|l|l|}
\hline Survey & Year & Region \\
\hline TAN0105 & Apr 2001 & Narrows Basin \\
\hline TAN0204 & Mar 2002 & South Narrows Basin \\
\hline TAN0211 & Aug 2002 & Campbell Plateau, Cook Strait Canyon \\
\hline TAN0215 & Oct 2002 & Cook Strait canyons \\
\hline TAN0309 & Jun 2003 & Northern Marlborough, Hikurangi Trough \\
\hline TAN0510 & Aug 2005 & Wairarapa Shelf - Hikurangi Trough \\
\hline
\end{tabular}

Table 2: Technical characteristics of NIWA's EM300 multibeam system

\begin{tabular}{|l|l|}
\hline Central Frequency & $32 \mathrm{kHz}$ \\
\hline Number of beams & 135 \\
\hline Beam width & $1^{\circ} 2^{\circ}$ (along * across track) \\
\hline Angular swath range & $140^{\circ}$ \\
\hline Overall swath coverage & $5.5^{*}$ water depth \\
\hline Water depth range & $150-3500 \mathrm{~m}$ \\
\hline Survey navigation systems & HydroPro and HydroMap \\
\hline $\begin{array}{l}\text { Positioning \& } \\
\text { Motion compensation }\end{array}$ & $\begin{array}{l}\text { TSS DMS } \\
\text { TSS POS-MV 320 system }\end{array}$ \\
\hline Sound velocity calibration & $\begin{array}{l}\text { Expendable Bathythermographs (XBTs) } \\
\text { Digibar DB-1100 } \\
\text { AML SVplus sound velocity profiler }\end{array}$ \\
\hline
\end{tabular}


Table 3. Simplified grain size classification from Blott and Pye (2000).

\begin{tabular}{|c|c|c|}
\hline$\varphi^{*}$ & $\boldsymbol{d}(\mathbf{m m})$ & Class \\
\hline$<-1.0$ & $>2.00$ & Gravel \\
\hline$-1.0-4.0$ & $2.00-0.063$ & Sand \\
\hline$>4$ & $<0.063$ & Mud \\
\hline$* \varphi=-\log 2 \mathrm{~d}, \mathrm{~d}$ grain diameter $(\mathrm{mm})$ \\
\hline
\end{tabular}

Table 4. Minimum and maximum processed backscatter values for Tan0105 survey.

\begin{tabular}{|c|c|c|c|c|c|c|c|c|c|c|}
\hline $\begin{array}{l}\text { Backscatter } \\
\text { Processing }\end{array}$ & \multicolumn{2}{|c|}{$\begin{array}{c}\text { Compensated } d^{\star \star} \\
(\mathrm{dB})\end{array}$} & \multicolumn{8}{|c|}{$\begin{array}{l}\text { Calibrated } \\
\left(\mathrm{dB} \text { re. } 1 \mathrm{~m}^{2}\right)\end{array}$} \\
\hline $\begin{array}{l}\text { Incidence } \\
\text { angles }^{++}\end{array}$ & \multicolumn{2}{|c|}{$-70^{\circ}$ to $70^{\circ}$} & \multicolumn{2}{|c|}{$\begin{array}{l}-70^{\circ} \text { to } 70^{\circ} \\
\text { (all swath) }\end{array}$} & \multicolumn{2}{|c|}{$\begin{array}{l}-10^{\circ} \text { to } 10^{\circ} \\
\text { (Specular) }\end{array}$} & \multicolumn{2}{|c|}{$\begin{array}{l}43^{\circ} \text { to } 47^{\circ} \\
\text { (BS45) }\end{array}$} & \multicolumn{2}{|c|}{$\begin{array}{l}68^{\circ} \text { to } 72^{\circ} \\
\text { (grazing) }\end{array}$} \\
\hline & all* & $3 \%$ & all* & $3 \%^{+}$ & all* & $3 \%^{+}$ & all* & $3 \%^{+}$ & all* & $3 \%^{+}$ \\
\hline Min & -65 & -34 & -55 & -38 & -47 & -23 & -47 & -36 & -54 & -42 \\
\hline Max & 12 & -16 & 18 & -9 & 16 & -1 & -11 & -18 & -9 & -22 \\
\hline Amplitude & 77 & 18 & 73 & 29 & 63 & 22 & 46 & 18 & 45 & 20 \\
\hline Mean & \multicolumn{2}{|c|}{$-25 \pm 5$} & \multicolumn{2}{|c|}{$-25 \pm 7$} & \multicolumn{2}{|c|}{$-12 \pm 6$} & \multicolumn{2}{|c|}{$-26 \pm 5$} & \multicolumn{2}{|c|}{$-31 \pm 6$} \\
\hline
\end{tabular}

* All angle of incidence $\left(-70^{\circ}\right.$ to $\left.70^{\circ}\right)$

** Statistical compensation undertaken by applying a gain function (C Figure $3 \mathrm{C}$ ). $\pm 1 \mathrm{~dB}$ absolute uncertainty.

*** Calibration undertaken by fitting a modelled pattern of array directivity on data recorded over homogeneous seafloor areas (see text). $\pm 1 \mathrm{~dB}$ absolute uncertainty.

+ Minimum and maximum values inside the $3 \%$ quantile

++ Positive incidence angles only as angular profiles are assumed symmetrical.

\# BS45 calculated between $43^{\circ}$ and $47^{\circ}$ incidence angles on both starboard and port sides. 
Table 5: Geological, geomorphological and b ackscatter $\mathrm{c}$ haracteristics of the eight test areas identifie $\mathrm{d}$ in the Narrows Basin. The six independent parameters $\left(A\right.$ to $F$ ) are generated from modelling of the angular response of the backscatter intensity. $B S$ values are in $\mathrm{dB}$ re. $1 \mathrm{~m}^{2}$. A $\pm 1 \mathrm{~dB}$ absolute uncertainty is assumed on all $B S$ values (see text).

\begin{tabular}{|c|c|c|c|c|c|c|c|c|c|}
\hline \multicolumn{2}{|l|}{ Area } & 1 & 2 & 3 & 4 & 5 & 6 & 7 & 8 \\
\hline \multicolumn{2}{|l|}{ Morphology } & $\begin{array}{l}\text { SE facing slope, } \\
\text { smooth }\end{array}$ & $\begin{array}{l}\text { Flat, shallow, } \\
\text { smooth }\end{array}$ & $\begin{array}{l}\text { Sedm't wave } \\
\text { field, basin floor }\end{array}$ & $\begin{array}{l}\text { Very shallow } \\
\text { rough }\end{array}$ & $\begin{array}{l}\text { Smooth deep basin } \\
\text { floor }\end{array}$ & Basin wall south & Basin wall central & $\begin{array}{l}\text { Smooth shallow } \\
\text { shelf }\end{array}$ \\
\hline \multicolumn{2}{|c|}{ Sediment Character* } & $\begin{array}{l}\text { muddy gravel, } \\
\text { med-fine sand, } \\
\text { very fine sand }\end{array}$ & $\begin{array}{l}\text { firm grey mud; } \\
\text { med-fine sand; } \\
\text { shingle }\end{array}$ & $\begin{array}{l}\text { mud; med-fine } \\
\text { sand }\end{array}$ & $\begin{array}{l}\text { Sandy to gravelly } \\
\text { mud, some } \\
\text { pebbles }\end{array}$ & $\begin{array}{l}\text { Coarse to very } \\
\text { coarse incl. pebbles } \\
\text { \& boulders }\end{array}$ & $\begin{array}{l}\text { Gravel, very coarse } \\
\text { sand concretion, } \\
\text { muddy sand }\end{array}$ & $\begin{array}{l}\text { gravel, sand, } \\
\text { pebbles } \\
\text { shelly muddy sand }\end{array}$ & $\begin{array}{l}\text { Muddy Sand; } \\
\text { Very Fine Gravel }\end{array}$ \\
\hline \multicolumn{2}{|l|}{ N. samples } & 43 & 26 & 15 & 45 & 43 & 24 & 11 & 2 \\
\hline \multicolumn{2}{|c|}{ Backscatter Imagery** } & $\begin{array}{l}\text { Moderately } \\
\text { weak }\end{array}$ & weak & very weak & strong & very strong & Moderately weak & $\begin{array}{c}\text { moderately weak } \\
\text { to weak }\end{array}$ & $\begin{array}{l}\text { Moderately } \\
\text { strong }\end{array}$ \\
\hline Specular level & $A$ & -8.7 & -8.5 & -9.8 & -12.9 & -3.9 & -7.2 & -5.5 & -11.3 \\
\hline Angular extent & $B$ & $3.6^{\circ}$ & $4.2^{\circ}$ & $5.3^{\circ}$ & $4.8^{\circ}$ & $9.5^{\circ}$ & $4.5^{\circ}$ & $3.9^{\circ}$ & $3.6^{\circ}$ \\
\hline Lambert ref. & $\mathrm{C}$ & -21.7 & -28.4 & -30.8 & -17.4 & -16.6 & -20.3 & -18.8 & -18.3 \\
\hline " decrement & $D$ & 1.9 & 2.2 & 2.2 & 2.5 & 2.1 & 2.2 & 2.8 & 2.2 \\
\hline Transitory level & $E$ & -17.9 & -18.8 & -20.6 & -16.6 & -15.4 & -19.2 & -15.8 & -15.5 \\
\hline Angular extent & $F$ & $10.1^{\circ}$ & $14.9^{\circ}$ & $15.0^{\circ}$ & $16.6^{\circ}$ & $11.2^{\circ}$ & $12.8^{\circ}$ & $10.3^{\circ}$ & $12.8^{\circ}$ \\
\hline $\mathrm{STOC}^{+}$ & $A-C$ & 12.9 & 19.8 & 21 & 4.5 & 13 & 13 & 13.3 & 7 \\
\hline$B S 45^{++}$ & BS45 & $-25.0 \pm 6.3$ & $-29.9 \pm 2.7$ & $-34.3 \pm 3.0$ & $-21.4 \pm 2.3$ & $-19.7 \pm 2.3$ & $-23.3 \pm 2.8$ & $-23.8 \pm 2.7$ & $-22.2 \pm 2.3$ \\
\hline
\end{tabular}

* From the Gradistat sediment grain size classification software (Blott and Pye, 2000)

** Based on the visual interpretation of the Figure 5.

+ Specular-To-Oblique Contrast $=\mathrm{A}-\mathrm{C}$ from equation (2).

++ Mean $B S 45$ calculated between $43^{\circ}$ and $47^{\circ}$ incidence angles on both starboard and port sides. 
Table 6 : Six parameters ( $A$ to $F$ ) generated fr om $B S$ angular responses models for characteristic mud, sand and gravely samples collected throughout the Cook Strait.

\begin{tabular}{|c|c|c|c|c|c|}
\hline & & Gravel & Sand & Mud & $\begin{array}{l}\text { Mud with } \\
\text { underlying } \\
\text { sediments }\end{array}$ \\
\hline \multicolumn{2}{|c|}{ Samples } & $\begin{array}{l}\text { C118 } \\
\text { C125 } \\
\text { C126 } \\
\text { C129 }\end{array}$ & $\begin{array}{c}\text { C61 } \\
\text { C62 } \\
\text { C90 } \\
\text { C229 }\end{array}$ & U630 & Q222B \\
\hline \multicolumn{2}{|c|}{ Gravel (\%) } & 100 & 10.65 & 0 & 0 \\
\hline \multicolumn{2}{|c|}{ Sand (\%) } & 0 & 83.25 & 1.5 & 6.9 \\
\hline \multicolumn{2}{|c|}{ Mud (\%) } & 0 & 6.1 & 98.5 & 93.1 \\
\hline Specular Level & $A^{*}$ & -9.1 & -9.1 & -13.6 & -6.1 \\
\hline Specular angular extent & $B$ & $4.9^{\circ}$ & $5.9^{\circ}$ & $5.5^{\circ}$ & $5.1^{\circ}$ \\
\hline Lambert Reference & $C^{*}$ & -17.9 & -23.9 & -29.1 & -27.3 \\
\hline Lambert Decrement & $D$ & 2 & 2 & 2 & 2 \\
\hline Transitory Level & $E^{*}$ & -17.5 & -20.9 & -24.5 & -20.7 \\
\hline Transitory angular extent & $F$ & $16.2^{\circ}$ & $17.9^{\circ}$ & $16.2^{\circ}$ & $12.4^{\circ}$ \\
\hline
\end{tabular}

* in $\mathrm{dB}$ re. $1 \mathrm{~m}^{2} . \mathrm{A} \pm 1 \mathrm{~dB}$ absolute uncertainty is assumed. 